\title{
Bank finance versus bond finance: what explains the differences between US and Europe?
}

\author{
Fiorella De Fiore* \\ Harald Uhlig**
}

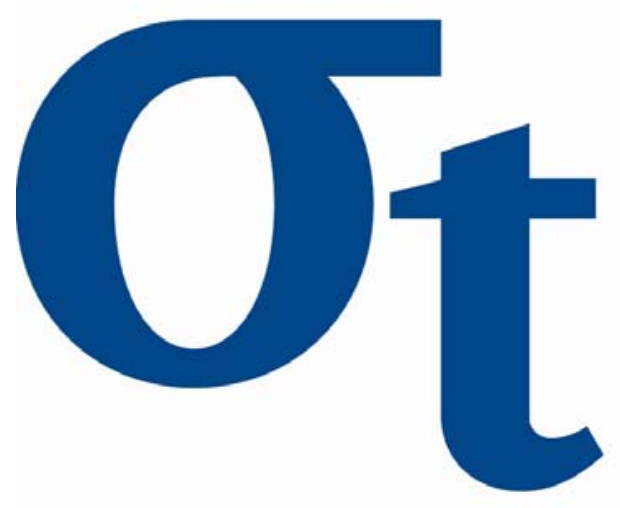

* European Central Bank

** Humboldt-Universität zu Berlin, Deutsche Bundesbank, CentER and CEPR 


\title{
Bank finance versus bond finance: what explains the differences between US and Europe?*
}

\author{
Fiorella De Fiore ${ }^{\dagger}$ \\ European Central Bank \\ Harald Uhlig ${ }^{\ddagger}$ \\ Humboldt Universität zu Berlin, Deutsche Bundesbank, CentER and CEPR
}

This version: 1 August 2005

\begin{abstract}
We present a dynamic general equilibrium model with agency costs, where heterogeneous firms choose among two alternative instruments of external finance - corporate bonds and bank loans. We characterize the financing choice of firms and the endogenous financial structure of the economy. The calibrated model is used to address questions such as: What explains differences in the financial structure of the US and the euro area? What are the implications of these differences for allocations? We find that a higher share of bank finance in the euro area relative to the US is due to lower availability of public information about firms' credit worthiness and to higher efficiency of banks in acquiring this information. We also quantify the effect of differences in the financial structure on per-capita GDP.

JEL Classification: E20, E44, C68.

Keywords: Financial structure, agency costs, heterogeneity.
\end{abstract}

${ }^{*}$ The views expressed here do not necessarily reflect those of the European Central Bank or the Eurosystem. We thank participants at the SED meetings, at the conferences on Dynamic Macroeconomics in Hydra, on DSGE Models and the Financial Sector in Eltville, on Competition, Stability and Integration in European Banking in Brussels, and seminar participants at Bocconi University. We are grateful to our discussants, Jajit Chada, Nobuhiro Kiyotaki, Andreas Schabert and Javier Suarez. This research was supported by the Deutsche Forschungsgemeinschaft through the SFB 649 "Economic Risk" and by the RTN network MAPMU.

${ }^{\dagger}$ Directorate General Research, European Central Bank, Postfach 160319, 60066 Frankfurt am Main, Germany. Email: fiorella.de_fiore@ecb.int. Ph: +49-69-13446330.

${ }^{\ddagger}$ School of Bus. \& Econ., WiPol 1, Humboldt University, Spandauer Str. 1, 10178 Berlin, Germany. Email: uhlig@wiwi.hu-berlin.de. http://www.wiwi.hu-berlin.de/wpol. Ph: +49-30-2093 5927. 


\section{Introduction}

This paper looks at the composition of the corporate sector's external finance as an important dimension through which credit market imperfections affect the macroeconomy. In the presence of agency costs, financial intermediaries provide contractual arrangements that reduce the effects of information asymmetries between lenders and borrowers. This is achieved by offering alternative financing instruments that best fit the needs of individual borrowers. Each instrument differs in the cost imposed to lenders and borrowers and in the ability to reduce the macroeconomic effects of information asymmetries.

Empirical evidence suggests substantial differences in the financial structure across countries. For instance, the traditional distinction between bank-based and market-based financial systems applies to the euro area and the US. Investment of the corporate sector relies much more heavily on bank finance in the euro area than in the US. In 2001, bank loans to the corporate sector amounted to 42.6 percent of GDP in the euro area, and to 18.8 percent in the US. Conversely, outstanding debt securities of non-financial corporations and stock market capitalization amounted respectively to 6.5 and 71.7 percent in the euro area, and to 28.9 and 137.1 percent in the US. ${ }^{1}$

In this paper, we introduce heterogeneous firms and alternative instruments of external finance in a dynamic general equilibrium model with agency costs. We characterize the optimal choice of firms among alternative instruments and derive the endogenous financial structure. The model can be used as a laboratory to answer questions such as: What generates differences in financial structures among countries? What are the implications of these differences for allocations?

Existing models with agency costs (e.g. Kiyotaki and Moore (1997), Carlstrom and Fuerst (1997, 1998, 2001), Bernanke, Gertler and Gilchrist (1999), Christiano, Motto and Rostagno (2004) and Faia (2002)) do not allow to explain observed differences in financial structures, as they do not distinguish between alternative instruments of external finance. We introduce two types of financial intermediaries - commercial banks and capital mutual funds - into an otherwise standard model with credit frictions and information asymmetries. Each type of financial intermediaries (here onwards FIs) offers a different intra-period contractual arrangement to provide external finance to firms. Firms experience a sequence of idiosyncratic productivity

\footnotetext{
${ }^{1}$ See Ehrmann et al (2003), Table 14.1.
} 
shocks, the first being realized before firms take financing decisions. Therefore, when choosing the source of external finance firms are heterogeneous in the risk they face of defaulting at the end of the period. Banks and capital mutual funds (CMFs) differ because banks are willing to spend resources to acquire information about firms in financial distress, while CMFs are not. Conditional on the information obtained, banks give firms the option to obtain loans and produce or to abstain from production and keep their initial net worth (except for an information acquisition fee to be paid to banks). The fact that banks spend resources to acquire information implies that bond finance is less costly than bank finance. Nonetheless, financing through bonds is a risky choice for firms, because a situation of financial distress can only be resolved with liquidation and with the complete loss of the firm's initial net worth.

The contribution of the paper is twofold. First, we present a dynamic general equilibrium model where the financial structure of the economy can be endogenously derived from the firms' optimal choice of the financing instrument. Our model can easily embed firms' heterogeneity in the risk of default without giving up tractability. The dynamics of the economy can be described by a system of aggregate equilibrium conditions similar to those arising in models without such heterogeneity. Second, we calibrate the model in steady state to replicate key differences in the financial structure of the US and the euro area. We find that a higher share of bank finance in the euro area relative to the US is due to lower availability of public information about firms' credit worthiness and to higher efficiency of banks in acquiring this information. We also assess the quantitative importance of differences in financial structures by comparing the observed ratios of per-capita GDP in versions of the calibrated model that allow for the use of one or two instruments of external finance.

A related paper to ours is Carlstrom and Fuerst (2001). The main difference is that in their model, firms are ex-ante identical at the time of stipulating a financial contract. ${ }^{2}$ Moreover, they have access to one financing instrument only. Therefore, in their framework it is not possible to address the importance of the composition of firms' external finance for the macroeconomy. Another difference arises in the focus of the analysis. Carlstrom and Fuerst address the effect of agency costs on the transmission of aggregate shocks. As our focus is

\footnotetext{
${ }^{2}$ In Calstrom and Fuerst (2001), at the time of the contract firms can differ in terms of size. However, due to the specific characteristic of the contract solution, this type of heterogeneity is not relevant in equilibrium and firms can be assumed identical ex-ante. In what follows, we will use the term 'ex-ante heterogeneity' as implying heterogeneity at the time of the contract in the risk of defaulting at the end of the period. This type of heterogeneity is also relevant in equilibrium.
} 
on the determinants of financial market structures, we restrict the attention to a steady state analysis.

Our paper also relates to recent theories of financial intermediation (e.g. Chemmanur and Fulghieri (1994) and Holstrom and Tirole (1997), among several others). We share with Chemmanur and Fulghieri (1994) the idea that banks treat differently borrowing firms in situations of financial distress because they are long-term players in the debt market while bondholders are not. Therefore, banks have an incentive to acquire a larger amount of information about firms. By minimizing the probability of their inefficient liquidation, banks build a reputation for financial flexibility and attract firms that are likely to face temporary situations of distress. The steady state distribution of firms arising in our model closely resembles that obtained by Holstrom and Tirole (1997) in a two-period model where firms and intermediaries are capital constrained. The authors find that poorly capitalized firms do not invest. Well capitalized firms finance their investment directly on the market, relying on cheaper, less-information intensive finance. Firms with intermediate levels of capitalization can invest, but only with the help of information-intensive external finance.

The paper proceeds as follows. In section 2, we describe the environment and outline the sequence of events. In section 3 , we present the analysis. We start by showing that in our economy the presence of agency costs translates into a firm-specific markup that entrepreneurs need to charge over marginal costs. We proceed to derive the optimal contract between firms and FIs, and we characterize the endogenous financial structure of the economy. We show that in each period, conditional on the realization of the first idiosyncratic shock, entrepreneurs split into three sets: entrepreneurs that decide to abstain from production, entrepreneurs that approach a bank and possibly obtain a loan, and entrepreneurs that raise external finance through CMFs. Finally, we describe the consumption and investment decisions of entrepreneurs and households, present aggregation results and characterize the competitive equilibrium. In section 4 , we illustrate the main properties of the model in steady state. In section 5 , we review the evidence on differences in the intermediation activities and in the financial structure of the corporate sector in the US and the euro area. Then, we present a calibration of the model that replicates in steady state the outlined key differences. Finally, we explore possible reasons for such differences and we look at the implications for allocations. In section 6 , we conclude and outline our future research. 


\section{The Model}

We cast the different role of corporate bonds and bank loans into a dynamic general equilibrium model with credit market frictions, where we maintain the assumption of one-period maturity of the debt.

The domestic economy is inhabited by a continuum of identical infinitely-lived households, a continuum of heterogeneous firms owned by infinitely lived risk-neutral entrepreneurs, and two types of zero-profit FIs. Each firm, indexed by $i \in[0,1]$, starts the period with an endowment of physical capital and with a constant returns to scale production technology that uses labor and capital as inputs. As the value of the initial capital stock is not sufficient to finance the input bill, producing firms need to raise external finance.

In our model, two key ingredients allow to introduce a non-trivial choice of firms among alternative instruments of external finance. The first ingredient is the existence of two distinct types of FIs, where banks are willing to spend resources to acquire information about an unobserved productivity factor, while CMFs are not. The second key ingredient is a sequence of three idiosyncratic productivity shocks hitting each firm. The first shock, $\varepsilon_{1, i t}$, is publicly observed and realizes before firms take financial and production decisions. The second shock, $\varepsilon_{2, i t}$, is not observed by anyone (not even the entrepreneur). Information on the realization of this shock can be acquired by the FIs at a cost that is proportional to the value of the firm and then disclosed to the firm in exchange of an up-front fee. The third shock, $\varepsilon_{3, i t}$, realizes after borrowing occurs and is observable to the entrepreneur only. It can be monitored by FIs at the end of the period, at a cost that is a fraction of the firm's production. The first shock generates observable heterogeneity among firms in the risk of default at the end of the period. The second shock, in combination with the information acquisition role of banks, provides the rationale for choosing bank finance for firms facing high risk of default. The combination of these two shocks is crucial to generate cross-sectional variation in firms' financing choices. Finally, the third shock introduces asymmetric information and rationalizes the existence of risky debt as the optimal contract between lenders and borrowers.

Loans extended by both types of FIs take the form of intra-period trade credit calculated in units of the output good, as in Carlstrom and Fuerst (2001). Firms obtain labor and capital inputs from the households against the promise to deliver the factor payments at the end of the period. This requires a contractual arrangement, which is supplied by a FI. 


\subsection{The environment}

\subsubsection{Households}

Households maximize the expected value of the discounted stream of future utilities,

$$
E_{0} \sum_{t=0}^{\infty} \beta^{t}\left[\ln c_{t}+\eta\left(1-l_{t}\right)\right], \quad 0<\beta<1,
$$

where $\beta$ is the households' discount rate, $c_{t}$ is consumption, $l_{t}$ denotes working hours and $\eta$ is a preference parameter. The households are also the owners of the FIs, to which they lend on a trade credit account to be settled at the end of each period. The representative household faces the budget constraints,

$$
c_{t}+k_{t+1}-(1-\delta) k_{t} \leq w_{t} l_{t}+r_{t} k_{t}
$$

where $w_{t}$ denotes the real wage and $r_{t}$ the rental rate on capital.

\subsubsection{Entrepreneurs}

Each entrepreneur $i$ enters the period holding capital $z_{i t}$. The firm operates a CRS technology described by

$$
y_{i t}=\varepsilon_{1, i t} \varepsilon_{2, i t} \varepsilon_{3, i t} H_{i t}^{\alpha} K_{i t}^{1-\alpha}
$$

where $K_{i t}$ and $H_{i t}$ denote the firm-level capital and labor, respectively. The productivity shocks $\varepsilon_{1, i t}, \varepsilon_{2, i t}$ and $\varepsilon_{3, i t}$ are random iid disturbances, which occur at different times during the period. They have mean unity, ${ }^{3}$ are mutually independent and have aggregate distribution functions denoted by $\Phi_{1}, \Phi_{2}$ and $\Phi_{3}$ respectively. Per independence assumption, these are also the marginal distributions. The entrepreneur faces the constraint that the available funds, $x_{i t}$, need to equal the costs of renting the factors of production,

$$
x_{i t}=w_{t} H_{i t}+r_{t} K_{i t}
$$

Entrepreneurs are infinitely lived, risk-neutral and more impatient than households. They discount the future at a rate $\beta \gamma$, where $\beta$ is the discount factor of households and $0<\gamma<1$. Entrepreneurial utility is linear in consumption and in effort. Running a risky project requires an entrepreneurial effort proportional to the size of the project, $x_{i t}$. Define $D_{i t}$ as a dummy

\footnotetext{
${ }^{3}$ An aggregate technology shock can be introduced by assuming that the mean $\varepsilon_{1 t}$ of the first entrepreneurspecific technology shock is not unitary.
} 
variable that takes the value of 1 if firm $i$ produces in period $t$ and of 0 if it does not. The problem is to maximize the expected value of the discounted stream of future utilities,

$$
E_{0} \sum_{t=0}^{\infty}(\beta \gamma)^{t}\left(e_{i t}-\chi x_{i t} D_{i t}\right), \quad 0<\gamma<1,
$$

subject to the budget constraint

$$
e_{i t}+z_{i t+1}=y_{i t}^{e}
$$

Here $e_{i t}$ denotes entrepreneurial consumption, $z_{i t+1}$ is investment in physical capital to be used in period $t+1$, and $y_{i t}^{e}$ is the share of the firm's production accruing to the entrepreneur after repayment of the loans. The parameter $\chi$ measures the disutility of exerting effort in running the project.

Notice that, because entrepreneurs are more impatient than households, they demand a higher internal rate of return to investment. This opens the room for trade between households and entrepreneurs despite the agency costs of external finance.

\subsubsection{Agency costs and financial intermediation}

Entrepreneurs obtain labor and capital inputs from the households against the promise to deliver the factor payments at the end of the period. Given the possibility of default by firms, this promise needs to be backed up by a contractual arrangement with a FI (a bank or a $\mathrm{CMF}$ ). The competitive FIs are able to diversify the risk among the continuum of firms facing idiosyncratic risk. Hence, they ensure repayment of the factors of production to the households despite the possibility of default by firms. Since credit arrangements are settled at the end of the same period, the intermediaries break exactly even on average.

Let $\omega_{i t}$ be the uncertain productivity factor at contracting time, when firms approach FIs,

$$
\omega_{i t}= \begin{cases}\varepsilon_{2, i t} \varepsilon_{3, i t} & \text { for CMF finance } \\ \varepsilon_{3, i t} & \text { for bank finance }\end{cases}
$$

Firms that decide to raise finance from banks pay an up-front fee that covers the bank's cost of information acquisition about the signal $\varepsilon_{2, i t}$. The fee is a fixed proportion $\tau$ of the firm's value $n_{i t}$. This cost is not faced by firms that sign a contract with CMFs, as these FIs do not acquire information about the unobserved shock. Hence, the disposable net worth of a firm at the time of the contract is given by $\tilde{n}_{i t}$, where

$$
\tilde{n}_{i t}= \begin{cases}n_{i t} & \text { for CMF finance } \\ (1-\tau) n_{i t} & \text { for bank finance }\end{cases}
$$


Conditional on $\varepsilon_{1, i t}$ and possibly $\varepsilon_{2, i t}$ as described in section 2.2 below, each entrepreneur chooses to invest an amount $0 \leq \widehat{n}_{i t} \leq \tilde{n}_{i t}$ of internal finance in the risky project and requests an amount $x_{i t}-\widehat{n}_{i t}$ of external finance to a FI to back up his promise of repayment, for total funds at hand of $x_{i t}$. Throughout the analysis, we assume that entrepreneurs cannot enter actuarily fair gambles with FIs.

Each FI is willing to finance a project whose size is a fixed proportion of the internal funds invested,

$$
x_{i t}=\xi \widehat{n}_{i t}, \quad \xi \geq 1
$$

This assumption captures the idea that entrepreneurs differ in their ability to run projects. In particular, the maximal size of a project which an entrepreneur is capable of running is proportional to his net worth.

After the realization of the uncertain productivity factor, $\omega_{i t}$, the entrepreneur observes the actual production in units of goods, $y_{i t}$, and announces to the FI repayment of the debt or default. The realization of $\omega_{i t}$ is only known to the firm unless there is costly monitoring, which requires destroying a fraction $\mu$ of the firm's output. After the announcement of the entrepreneur, the FI decides whether or not to monitor.

The informational structure at contracting time corresponds to the costly state verification (CSV) framework of Townsend (1979) and Gale and Hellwig (1985). ${ }^{4}$ A standard result of this framework is that the optimal contract between each firm and FI is risky debt. The contract specifies how to divide the firm's financing requirement into internal and external finance. It also specifies, for each announced output and prior information $\left(\varepsilon_{1, i t}\right.$ under CMF finance and $\varepsilon_{1, i t} \varepsilon_{2, i t}$ under bank finance), a threshold for the uncertain productivity factor, $\omega_{i t}$. The firm defaults and the FI commits to monitor if the entrepreneur's announcement of $\omega_{i t}$ is below this threshold. If there is monitoring, $\omega_{i t}$ is made known to the FI and the firm's production is completely seized. The contract also sets a fixed repayment for firms that do not default.

\subsection{The timing of events}

The following list provides an overview of the timing of events in period $t$.

\footnotetext{
${ }^{4}$ Restriction (7) is usually not imposed in the costly state verification literature. It is necessary in our model economy to ensure that all firms raise finite amounts of external finance, despite the presence of ex-ante heterogeneity. Such assumption and its consequences are discussed in greater detail in section 3.2.1.
} 
Entrepreneurs and households enter the period holding respectively capital $z_{i t}$ and $k_{h t}$. Households plan, how much labor to supply, and how much consumption and investment goods to purchase. They also supply labor and rent out their capital stock. Entrepreneurs calculate the end-of-period value $n_{i t}$ of their capital holdings $z_{i t}$, which is publicly observable.

Financial decisions unfold over three stages.

I. The first entrepreneur-specific shock $\varepsilon_{1, i t}$ is realized and publicly observed. Conditional on its realization, entrepreneurs decide whether to:

a. Abstain from production. Entrepreneurs facing a low $\varepsilon_{1, i t}$, or a high risk of default, decide not to borrow and not to produce, i.e. they choose $\widehat{n}_{i t}=0$. They rent out capital on the market, thus retaining their initial net worth, $n_{i t}$, until the end of the period.

b. Possibly borrow from banks and produce. Entrepreneurs facing an intermediate realization of $\varepsilon_{1, i t}$ decide to approach a bank and to postpone their production decision after the realization of the second productivity shock $\varepsilon_{2, i t} .^{5}$

c. Borrow from CMFs and produce. Entrepreneurs facing a high realization of $\varepsilon_{1, i t}$ decide to raise external finance from CMFs and not to acquire information on $\varepsilon_{2, i t}$.

II. $\varepsilon_{2, i t}$ is realized and not observed by anyone. Information on its realization is acquired by banks at a cost $\tau n_{i t}$ and communicated to entrepreneurs. Conditional on $\varepsilon_{2, i t}$, entrepreneurs choose their investment level $0 \leq \widehat{n}_{i t} \leq \tilde{n}_{i t}=(1-\tau) n_{i t}$, i.e. whether to:

d. Abstain from production, in which case $\widehat{n}_{i t}=0$. These entrepreneurs rent out capital, retaining their remaining net worth, $(1-\tau) n_{i t}$, until the end of the period.

e. Borrow from banks and produce.

III. Entrepreneurs that have chosen to produce hire labor $H_{i t}$ and rent capital $K_{i t}$ from the households against the promise to deliver the factor payments at the end of the period.

\footnotetext{
${ }^{5}$ At this point, one could introduce the possibilities for entrepeneurs to enter actuarily fair gambles. It turns out that entrepreneurs would enter these gambles, and transfer their entire net worth to those entrepreneurs which draw the highest values of $\varepsilon_{2}$. Equivalently, one could assume that banks are allowed to cross-subsidize projects. They would take resources from low- $\varepsilon_{2}$ entrepreneurs and give them to high- $\varepsilon_{2}$ entrepreneurs. Here we effectively outlaw gambling and cross-subsidization, as common in the literature. An assumption which can rule out the benefits of such gambles is sufficient risk aversion for the entrepreneurs. This, however, would substantially increase the complexity of the model.
} 
This promise is backed up by the value of their own capital holdings plus the value of the additional trade credit obtained from the FI (either a bank or a CMF).

The third shock $\varepsilon_{3, i t}$ is realized and observed by the entrepreneur only. Production takes place, $y_{i t}=\varepsilon_{1, i t} \varepsilon_{2, i t} \varepsilon_{3, i t} H_{i t}^{\alpha} K_{i t}^{1-\alpha}$. The entrepreneurs keep part of output, $y_{i t}^{e}$, for own consumption and investment, and sell the rest to households to settle trade credit. Entrepreneurs announce the outcome of production and repay loans or default on loans, if they cannot repay the agreed-upon amount. Conditional on the announcement, the financial intermediaries decide whether or not to monitor.

Entrepreneurs consume $e_{i t}$ and accumulate capital $z_{i, t+1}$. Households use the goods purchased for consumption $c_{t}$ and investment in capital $k_{h, t+1}$.

\section{Analysis}

First, we show that the presence of agency costs translates into a firm-specific markup that entrepreneurs need to charge over marginal costs. Then, we characterize the contract between each firm and FI, and we derive the endogenous financial structure. We proceed by characterizing consumption and investment decisions of entrepreneurs and households. Finally, we present aggregation results and characterize the competitive equilibrium.

\subsection{Factor prices and the markup}

Each entrepreneur's net worth, $n_{i t}$, is given by the market value of his accumulated capital stock, $z_{i t}$, calculated as the to-be-earned factor payments plus the depreciated capital stock, ${ }^{6}$

$$
n_{i t}=\left(1-\delta+r_{t}\right) z_{i t},
$$

Firms that produce need to sign a contract with the FIs to raise external finance for total funds at hand $x_{i t}$. Normalizing goods prices, the firm's demand for labor and capital is derived by solving the problem

$$
\max \mathcal{E}\left[\varepsilon_{1, i t} \varepsilon_{2, i t} \varepsilon_{3, i t} H_{i t}^{\alpha} K_{i t}^{1-\alpha}-w_{t} H_{i t}-r_{t} K_{i t}\right]
$$

\footnotetext{
${ }^{6}$ One possible interpretation is that entrepreneurs sell their capital stock at the beginning of the period against trade credit $n_{i t}$. Notice that entrepreneurs' net worth should include also a fixed income component (e.g. a constant lump-sum subsidy $\psi$ ). This would ensure that, if the entrepreneur defaults in period $t-1$, he can obtain external finance and eventually produce. Since introducing a small constant subsidy does not affect the analysis, we abstract from it.
} 
subject to the financing constraint (4). Here the expectation $\mathcal{E}[\cdot]$ is taken with respect to the productivity variables yet unknown at the time of the factor hiring decision. More precisely,

$$
\mathcal{E}\left[\varepsilon_{1, i t} \varepsilon_{2, i t} \varepsilon_{3, i t}\right]= \begin{cases}\varepsilon_{1, i t} & \text { for CMF financed firms } \\ \varepsilon_{1, i t} \varepsilon_{2, i t} & \text { for bank financed firms }\end{cases}
$$

Denote the Lagrange multiplier on the financing constraint as $s_{i t}-1$. Optimality implies that

$$
\begin{aligned}
K_{i t} & =(1-\alpha) \frac{x_{i t}}{r_{t}} \\
H_{i t} & =\alpha \frac{x_{i t}}{w_{t}} \\
\mathcal{E}\left[y_{i t}\right] & =s_{i t} x_{i t} .
\end{aligned}
$$

where

$$
\begin{gathered}
s_{i t}= \begin{cases}\varepsilon_{1, i t} q_{t} & \text { for CMF finance } \\
\varepsilon_{1, i t} \varepsilon_{2, i t} q_{t} & \text { for bank finance }\end{cases} \\
q_{t}=\left(\frac{\alpha}{w_{t}}\right)^{\alpha}\left(\frac{1-\alpha}{r_{t}}\right)^{1-\alpha} .
\end{gathered}
$$

We can interpret $q_{t}$ as an aggregate distortion in production arising from the presence of agency costs in the economy. Notice that $s_{i t}$ acts as a markup, which firms need to charge in order to cover the agency costs of financial intermediation. Moreover, $s_{i t}$ is firm-specific: depending on what is already known about final firm productivity, i.e. depending on $\varepsilon_{1, i t}$ and (for bank-financed firms) $\varepsilon_{2, i t}$, the financing constraint may be more or less severe. ${ }^{7}$

\subsection{Financial structure}

In our model, the financial contract is intra-period but the game between firms and FIs unfolds over three stages (described in section 2.2). To derive the endogenous financial structure, we solve the model using backward induction.

First, we derive the optimal choice of agents in stage III. Conditional on the available prior information ( $\varepsilon_{1, i t}$ under bank finance and $\varepsilon_{1, i t} \varepsilon_{2, i t}$ under bank finance), firms and FIs stipulate a contract that is the optimal solution to a costly state verification (CSV) problem.

Then, we characterize the optimal choice of agents in stage II. Firms that have signed contracts with banks acquire at a cost information about $\varepsilon_{2, i t}$, on the basis of which they decide whether or not to abstain from production. The decision is taken conditional on the

\footnotetext{
${ }^{7}$ In Carlstrom and Fuerst (2001), as in most of the literature, nothing is known before firms produce, i.e., $\mathcal{E}\left[\varepsilon_{1, i t} \varepsilon_{2, i t} \varepsilon_{3, i t}\right]=1$ and $s_{i t}=q_{t}$.
} 
solution of the game in stage III (the financial contract) and on the available prior information $\left(\varepsilon_{1, i t} \varepsilon_{2, i t}\right)$. We characterize thresholds for the realization of the observed firm-specific markup $s_{i t}$ that determine the firm's decision of whether or not to borrow and to produce.

Finally, we characterize the optimal decision in stage I. Conditional on the solution of stage II and III (which provides expected pay-off from producing when raising external finance through banks or CMFs), firms decide whether or not to produce and, if they do, which instrument of external finance to use. We derive thresholds for the realization of the observed firm-specific markup $s_{i t}$ that determine the firm's decision. We show that these thresholds depend only on the distributional assumptions on the three idiosyncratic productivity shocks.

\subsubsection{The costly state verification contract}

The solution to our CSV problem is a standard debt contract (see e.g. Gale and Hellwig (1985)) that is characterized by three properties. First, the repayment to the FI is constant in states when monitoring does not occur. Second, the firm is declared bankrupt if and only if the fixed repayment cannot be honoured. Third, in case of bankruptcy, the FI commits to monitor and completely seizes the output in the hands of the firm. The first and third properties ensure that the contract is incentive compatible. The second property ensures that monitoring is done in as few circumstances as possible to avoid the deadweight loss.

Let $\Phi_{\omega}$ and $\varphi_{\omega}$ be respectively the distribution and density function of $\omega_{i t}$ and recall that the presence of agency costs implies that $y_{i t}=s_{i t} \omega_{i t} x_{i t}$. Define

$$
\begin{gathered}
f\left(\bar{\omega}^{j}\right)=\int_{\bar{\omega}^{j}}^{\infty}\left(\omega-\bar{\omega}^{j}\right) \Phi_{\omega}(d \omega) \\
g\left(\bar{\omega}^{j}\right)=\int_{0}^{\bar{\omega}^{j}} \omega \Phi_{\omega}(d \omega)-\mu \Phi_{\omega}\left(\bar{\omega}^{j}\right)+\bar{\omega}^{j}\left[1-\Phi_{\omega}\left(\bar{\omega}^{j}\right)\right]
\end{gathered}
$$

as the expected shares of final output accruing respectively to an entrepreneur and to a lender, after stipulating a contract that sets the fixed repayment at $s_{i t} \bar{\omega}_{i t}^{j} x_{i t}$ units of output, for $j=b, c$. The index $j$ denotes the type of FI, where $b$ indicates banks and $c$ indicates CMFs. The optimal contract solves the following CSV problem:

$$
\max \left[s_{i t} f\left(\bar{\omega}_{i t}^{j}\right)-\chi\right] x_{i t}
$$


subject to constraint (7) and

$$
\begin{aligned}
s_{i t} g\left(\bar{\omega}_{i t}^{j}\right) x_{i t} & \geq x_{i t}-\widehat{n}_{i t} \\
f\left(\bar{\omega}_{i t}^{j}\right)+g\left(\bar{\omega}_{i t}^{j}\right) & \leq 1-\mu \Phi_{\omega}\left(\bar{\omega}_{i t}^{j}\right) \\
\widehat{n}_{i t} & \geq 0,\left[s_{i t} f\left(\bar{\omega}_{i t}^{j}\right)-\chi\right] x_{i t} \geq \widehat{n}_{i t}
\end{aligned}
$$

The optimal contract maximizes the entrepreneur's expected utility subject to the restriction on the project size, (7), the lender being willing to lend out funds, (14), the feasibility condition, (15), and the entrepreneur being willing to sign the contract, (16). Since loans are intra-period, the opportunity cost of lending for the intermediary equals the amount of loans itself, $x_{i t}-\widehat{n}_{i t}$.

Notice that constraint (7) usually does not appear in the standard CSV setup. When firms are identical in terms of default risk, the contract determines optimally the size of the project. This latter turns out to be linear in net worth, as in our model. However, when firms are identical the ratio of the project size to net worth depends on the threshold for the idiosyncratic shock and on the aggregate variable $q_{t}$, while it is constant in our model. This implies that leverage is fixed in our environment. The reason for this assumption is that, with heterogeneity in the risk of default, firms differ in terms of credit-worthiness. When the distribution of the idiosyncratic shock $\varepsilon_{1 t}$ is unbounded, the optimal project size for firms experiencing extremely large values of that shock would be unbounded. To avoid corner solutions in the allocation of funds from FIs, we set the project size to a fixed share of the firm's initial net worth. This assumption ensures that all firms raise finite amounts of external finance.

Proposition 1 Under the optimal contract, the entrepreneur either invests nothing, $\widehat{n}_{i t}=0$, or invest his entire net worth, $\widehat{n}_{i t}=\tilde{n}_{i t}$, requiring an amount $(\xi-1) \tilde{n}_{i t}$ of external finance. The optimal contract is characterized by a threshold $\bar{\omega}_{i t}^{j}, j=b, c$, such that, if the entrepreneur announces a realization of the uncertain productivity factor $\omega \geq \bar{\omega}^{j}$, no monitoring occurs. If $\omega<\bar{\omega}^{j}$, the FI monitors at a cost and completely seizes the resources in the hands of the entrepreneur. The threshold is given by the solution to

$$
s_{i t} g\left(\bar{\omega}_{i t}^{j}\right)=\frac{\xi-1}{\xi} .
$$

Proof: Condition (7) and (16) imply that the expected utility of entrepreneurs willing to produce is not lower than the utility from disposing of the net worth initially invested. Notice that the problem is linear in $\widehat{n}_{i t}$. Thus, the solution is such that the entrepreneur either invest 
nothing and does not produce, $\widehat{n}_{i t}=0$, or invest everything and produce, $\widehat{n}_{i t}=\tilde{n}_{i t}$. Entrepreneurs that produce only raise costly external finance to cover what is needed in excess of the internal funds, $x_{i t}-\tilde{n}_{i t}=(\xi-1) \tilde{n}_{i t}$. Expression (17) for the threshold $\bar{\omega}_{i t}^{j}$ can be derived by observing that $f(0)=\int_{0}^{\infty} \omega \Phi_{\omega}(d \omega)=1, g(0)=0, f^{\prime}\left(\bar{\omega}_{i t}^{j}\right)=-\left[1-\Phi_{\omega}\left(\bar{\omega}_{i t}^{j}\right)\right]<0$, and $g^{\prime}\left(\bar{\omega}_{i t}^{j}\right)>0$. This latter property can be shown by contradiction. Suppose $g^{\prime}\left(\bar{\omega}_{i t}^{j}\right)<0$. Then, it would be possible to increase expected utility of the firm, $\left[s_{i t} f\left(\bar{\omega}_{i t}^{j}\right)-\chi\right] \xi \tilde{n}_{i t}$, by reducing $\bar{\omega}_{i t}^{j}$ while increasing expected profits of the FI, $s_{i t} g\left(\bar{\omega}_{i t}^{j}\right) \xi \tilde{n}_{i t}$. Hence, $\bar{\omega}_{i t}^{j}$ could not be a solution to the contract. It follows that the unique interior solution to the problem is given by (17).

The terms of the contract can be written as

$$
\bar{\omega}_{i t}^{j}=\bar{\omega}^{j}\left(s_{i t}\right), \quad j=b, c
$$

where $s_{i t}$ satisfies (9). Notice that $\frac{\partial \bar{\omega}_{i t}^{j}}{\partial s_{i t}}=-\frac{g\left(\bar{\omega}_{i t}^{j}\right)}{s_{i t} g^{\prime}\left(\bar{\omega}_{i t}^{j}\right)}<0$ and hence $\frac{\partial \bar{\omega}_{i t}^{j}}{\partial q_{t}}<0$. The higher the firm-specific mark-up $s_{i t}$ or $q_{t}$, the lower the threshold, $\bar{\omega}_{i t}^{j}$, below which the entrepreneur defaults and is monitored. Given the solution to the contract, we can define the risk premium $r_{i t}^{j}$ as the interest rate charged for the use of external finance. It is implicitly given by the condition $\left(1+r_{i t}^{j}\right)\left(x_{i t}-\tilde{n}_{i t}\right)=s_{i t} \bar{\omega}_{i t}^{j} x_{i t}$.

\subsubsection{Bank loan continuation}

At the beginning of stage II, the second productivity shock, $\varepsilon_{2, i t}$, is realized and not observed by anyone. Information on this shock is acquired by banks and communicated to the entrepreneur. Conditional on the realization of $\varepsilon_{2, i t}$, the entrepreneur chooses whether to abstain from production or to obtain trade credit and produce.

Proposition $2 A$ threshold for $s_{i t}=\varepsilon_{1, i t} \varepsilon_{2, i t} q_{t}$, below which the entrepreneur does not proceed with the bank loan, exists and is unique. It is given by a constant $s_{d}$ that satisfies

$$
\left[s_{i t} f\left(\bar{\omega}^{b}\left(s_{i t}\right)\right)-\chi\right] \xi=1 .
$$

Proof: Consider the situation of a firm that, upon payment of the information acquisition fee, $\tau n_{i t}$, observes $\varepsilon_{1, i t}$ and $\varepsilon_{2, i t}$. The entrepreneur proceeds with the bank loan if and only if his expected utility exceeds the opportunity costs of renting his capital to others, i.e. if $\left[s_{i t} f\left(\bar{\omega}^{b}\left(s_{i t}\right)\right)-\chi\right] \xi \geq 1$, where $s_{i t}=\varepsilon_{1, i t} \varepsilon_{2, i t} q_{t}$. Notice that expected utility from proceeding with the bank is negative for $s_{i t}=0$ and strictly increasing in $s_{i t}$, since $f^{\prime}\left(\bar{\omega}_{i t}^{b}\right)<0$ and $\frac{\partial \bar{\omega}_{i t}^{b}}{\partial s_{i t}}<$ 
0. Hence, a solution to condition (19), taken with equality, exists and is unique. Moreover, it is constant across firms and time.

Consider for a moment an environment where banks are allowed to cross-subsidize firms. Each firm would decide at the beginning of stage II whether or not to exchange its net worth for an actuarily fair gamble. The gamble would set an up-front fee and a repayment to the bank, which would depend on the prior available information, $\varepsilon_{1, i t}$, and the unobserved shock, $\varepsilon_{2, i t}$. In appendix $\mathrm{A}$, we show that the optimal financial arrangement would be one where banks cross-subsidize firms. With $\varepsilon_{2, i t}$ below a certain threshold, the firm would not produce but the bank would seize completely its net worth. With $\varepsilon_{2, i t}$ above that threshold, the firm would get full funding at the lowest possible cost. Repayments of producing firms would be minimized and so would be the probability of default and expected monitoring costs. The contract with cross-state subsidization would be optimal because it would minimize agency costs, increasing the aggregate resources available for entrepreneurial consumption and hence improving welfare of the risk-neutral entrepreneurs. It might be of interest to investigate the resulting general equilibrium effects in such an environment. However, a frequent objection to contracts that allow for cross-state subsidization is that lotteries are not observed in financial markets. One possible explanation is that investors are risk-averse, an element that is neglected in standard models with agency costs. For this reason, we do not allow firms to gamble.

\subsubsection{The choice of the financing instrument}

In stage I, after $\varepsilon_{1, i t}$ realizes, the entrepreneur chooses whether or not to produce and, if he does, how to finance production. For notational simplicity, we drop the subscripts.

The expected utility of an entrepreneur, who proceeds with bank finance conditional on the realization of $\varepsilon_{1}$, is $F^{b}(s) n$, where $s=\varepsilon_{1} q$ and

$$
F^{b}(s)=(1-\tau)\left(\int_{\frac{s_{d}}{s}} s \varepsilon_{2} f\left(\bar{\omega}^{b}\left(s \varepsilon_{2}\right)\right) \xi \Phi_{2}\left(d \varepsilon_{2}\right)-\chi \xi\left[1-\Phi_{2}\left(\frac{s_{d}}{s}\right)\right]+\Phi_{2}\left(\frac{s_{d}}{s}\right)\right)
$$

The possibility for the entrepreneur to await the further news $\varepsilon_{2}$ before deciding whether or not to proceed with the bank loan provides option value.

The expected utility of an entrepreneur, who proceeds with CMF finance conditional on the realization of $\varepsilon_{1}$, is $F^{c}(s) n$, where $s=\varepsilon_{1} q$ and

$$
F^{c}(s)=\left[s f\left(\bar{\omega}^{c}(s)\right)-\chi\right] \xi
$$


Finally, the expected utility of an entrepreneur, who abstains from production, is simply $n$. Note in particular, that all payoff functions are linear in net worth $n$.

Knowing its own mark-up $s=\varepsilon_{1} q$, each entrepreneur chooses his or her best option, leading to the overall payoff $F(s) n$, where

$$
F(s)=\max \left\{1 ; F^{b}(s) ; F^{c}(s)\right\}
$$

Conditional on $s$, entrepreneurs split into three sets: $\Omega_{a t}$, the set of entrepreneurs that abstain from raising external finance in period $t ; \Omega_{b t}$, the set of entrepreneurs that sign a contract with banks, and $\Omega_{c t}$, the set of CMF-financed entrepreneurs. We show that these three sets are intervals in terms of the first idiosyncratic productivity shock $\varepsilon_{1}$.

In the analysis below, we assume that conditions (A1) and (A2) are satisfied.

(A1) $F^{b \prime}(s) \geq 0$

$(A 2) F^{b \prime}(s)<F^{c \prime}(s)$, for all $s=\varepsilon_{1} q$.

Assumptions $(A 1)$ and $(A 2)$ impose mild restrictions on the parameters of the model. A sufficient condition for $(A 1)$ to be satisfied is that $\varphi_{\varepsilon_{2}}\left(\frac{s_{d}}{s}\right)<1$, since $s_{d} f\left(\bar{\omega}^{b}\left(s_{d}\right)\right) \xi=1+\chi \xi$ and $f^{\prime}\left(\bar{\omega}^{b}\right) \frac{\partial \bar{\omega}^{b}}{\partial\left(\varepsilon_{2} s\right)}>0$. The condition imposed by $(A 2)$ is also mild. Intuitively, firms with a low realization of the productivity shock $\varepsilon_{1}$ (a low $s$ ) have expectations of low returns from undertaking production after signing a contract with the bank, as represented by the first two terms in brackets, in the expression for $F^{b}(s)$. For those firms, the gain from minimizing the possibility of liquidation, $(1-\tau) \Phi_{2}\left(\frac{s_{d}}{s}\right)$, is relatively more important. If $s$ increases, the expected return from production increases both for bank- and for CMF-financed firms. However, the increase is higher under CMF finance because intermediation costs are lower. Hence, there will be a threshold above which expected profits from production for CMF-financed firms exceed those for bank-financed firms. $(A 1)$ and $(A 2)$ ensure uniqueness of the thresholds $s_{b}$ and $s_{c}$.

Proposition 3 Under (A1), a threshold for $s=\varepsilon_{1} q$, below which the entrepreneur decides not to raise external finance, exists and is unique. It is given by a constant $s_{b}$ that satisfies

$$
F^{b}(s)=1
$$

Proof: Notice that $F^{b}(0)=1-\tau$. Under (A1), there is a unique cutoff point $s_{b}$, which satisfies the condition $F^{b}(s)=1$. This point is constant across firms and time. 
Proposition 4 Under (A1) and (A2), a threshold for $s=\varepsilon_{1} q$ above which entrepreneurs sign a contract with the CMF, exists and is unique. It is given by a constant $s_{c}$ that satisfies

$$
F^{b}(s)=F^{c}(s)
$$

Proof: Notice that, $F^{b}(0)=1-\tau>F^{c}(0)$. A sufficient condition for existence and uniqueness of a threshold $s_{c}$ is provided by $(A 1)$ and $(A 2)$. The threshold is constant across firms and time.

Conditional on $q_{t}$, entrepreneurs split into three sets that are intervals in terms of the first idiosyncratic productivity shock $\varepsilon_{1, i t}$,

$$
\begin{aligned}
\Omega_{a t} & =\left\{\varepsilon_{1, i t} \mid \varepsilon_{1, i t}<s_{b} / q_{t}\right\} \\
\Omega_{b t} & =\left\{\varepsilon_{1, i t} \mid s_{b} / q_{t} \leq \varepsilon_{1, i t} \leq s_{c} / q_{t}\right\} \\
\Omega_{c t} & =\left\{\varepsilon_{1, i t} \mid \varepsilon_{1, i t}>s_{c} / q_{t}\right\}
\end{aligned}
$$

for some constants $s_{b}, s_{c}$. Notice that an increase in $q_{t}$ raises expected profits from producing, conditional on the realization of $\varepsilon_{1, i t}$, and reduces the thresholds $s_{b} / q_{t}$ and $s_{c} / q_{t}$. Hence, it decreases the share of firms that decide to abstain from production and increases the share of firms that sign a contract with FIs. Notice also that condition (19) determines a threshold $s_{d}$ for the firm-specific markup, below which firms that have signed a contract with banks decide to abstain. A corresponding threshold for the second firm-specific shock $\varepsilon_{2, i t}$ can be computed as $s_{d} /\left(q_{t} \varepsilon_{1, i t}\right)$. Conditional on the realization of $\varepsilon_{1, i t}$, an increase in $q_{t}$ reduces this threshold and the share of firms that decide to abstain conditional on having signed a contract with a bank. The firm's decision on whether or not to produce can be characterized by

$$
D_{i t}=\left\{\begin{array}{c}
1 \text { if } \varepsilon_{1, i t}>s_{c} / q_{t} \text { or if } s_{b} / q_{t} \leq \varepsilon_{1, i t} \leq s_{c} / q_{t} \text { and } \varepsilon_{2, i t}>s_{d} / \varepsilon_{1, i t} q_{t} \\
0 \text { else }
\end{array}\right.
$$

\subsection{Consumption and investment decisions}

Consumption and investment decisions of the households are described by the solution to the maximization problem (1) subject to (2), which is given by

$$
\begin{aligned}
\eta c_{t} & =w_{t} \\
\frac{1}{c_{t}} & =\beta E_{t}\left\{\frac{1}{c_{t+1}}\left(1-\delta+r_{t+1}\right)\right\} .
\end{aligned}
$$


The entrepreneurial decision on consumption and on investment in capital, which will be used as net worth in the following period, derives from the maximization of (5) subject to (6), where $y_{i t}^{e}=\tilde{n}_{i t}$ if firm $i$ abstains, $y_{i t}^{e}=s_{i t}\left(\omega_{i t}-\bar{\omega}_{i t}^{j}\right) \xi \tilde{n}_{i t}$ if firm $i$ borrows and repays, and $y_{i t}^{e}=0$ if firm $i$ borrows and default. The optimality condition is then given by the intertemporal Euler equation

$$
1=\beta \gamma E_{t}\left\{\left(1-\delta+r_{t+1}\right) F\left(\varepsilon_{1, i t+1} q_{t+1}\right)\right\}
$$

Observe that $q_{t+1}$ depends on $w_{t+1}$ and $r_{t+1}$ through (10). This equation ties down a relationship between these two factor prices. It also pins down the evolution of net worth of the entrepreneurs, since they will elastically save and supply capital, so that factor prices satisfy this equation exactly period by period.

\subsection{Aggregation}

We are now ready to calculate aggregate variables. Given $q_{t}$ and total entrepreneurial net worth $n_{t}$, we can compute total demand for funds, $x_{t}$, total output including agency costs, $y_{t}$, and total output lost to agency costs, $y_{t}^{a}$, by integrating across firms. The conditions are:

$$
\begin{aligned}
x_{t} & =\psi^{x}\left(q_{t} ; s_{b}, s_{c}, s_{d}\right) \xi n_{t} \\
y_{t} & =\psi^{y}\left(q_{t} ; s_{b}, s_{c}, s_{d}\right) q_{t} \xi n_{t} \\
y_{t}^{a} & =\psi^{a}\left(q_{t} ; s_{b}, s_{c}, s_{d}\right) \mu q_{t} \xi n_{t},
\end{aligned}
$$

where the functions $\psi^{x}(\cdot), \psi^{y}(\cdot)$ and $\psi^{a}(\cdot)$ are defined in Appendix C.

Aggregate entrepreneurial consumption and investment have to satisfy the constraint

$$
e_{t}+z_{t+1}=\vartheta\left(q_{t} ; s_{b}, s_{c}, s_{d}\right) n_{t}
$$

where the function $\vartheta(\cdot)$ is also defined in Appendix C.

Finally, aggregate factor demands are given by

$$
\begin{aligned}
w_{t} H_{t} & =\alpha x_{t} \\
r_{t} K_{t} & =(1-\alpha) x_{t} .
\end{aligned}
$$




\subsection{Market clearing}

Market clearing for capital, labor and output requires that

$$
\begin{aligned}
& K_{t}=k_{t}+z_{t}, \\
& H_{t}=l_{t}, \\
& y_{t}=c_{t}+e_{t}+y_{t}^{a}+K_{t+1}-(1-\delta) K_{t} .
\end{aligned}
$$

Market clearing for loans is ensured by condition (4), which equates the total funds available (i.e. the sum of internal and external finance) to the demand of funds.

\subsection{Competitive equilibrium}

Given the process of the idiosyncratic shocks, $\left\{\varepsilon_{1, i t}, \varepsilon_{2, i t}, \varepsilon_{3, i t}\right\}$, and the initial conditions $\left(k_{0}, z_{0}\right)$, a competitive equilibrium consists of sequences of firm-specific mark-ups, $\left\{s_{i t}\right\}_{t=0}^{\infty}$, threshold levels for the uncertain productivity factor $\left\{\bar{\omega}^{b}\left(s_{i t}\right), \bar{\omega}^{c}\left(s_{i t}\right)\right\}_{t=0}^{\infty}$, constant thresholds for the firm's mark-up $\left\{s_{b}, s_{c}, s_{d}\right\}_{t=0}^{\infty}$, production decisions $\left\{D_{i t}\right\}_{t=0}^{\infty}$, demand functions for labor and capital $\left\{H_{i t}, K_{i t}\right\}_{t=0}^{\infty}$, and consumption and investment decisions $\left\{e_{i t}, z_{i, t+1}\right\}_{t=0}^{\infty}$, for $i \in$ $(0,1)$. It also consists of aggregate factors $\left\{q_{t}\right\}_{t=0}^{\infty}$, allocations $\left\{c_{t}, l_{t}, H_{t}, K_{t}, e_{t}, x_{t}, y_{t}, y_{t}^{e}, y_{t}^{a}\right\}_{t=0}^{\infty}$, laws of motion for the capital stocks $\left\{k_{t+1}, z_{t+1}\right\}_{t=0}^{\infty}$, and prices $\left\{w_{t}, r_{t}\right\}$ such that:

- Households maximize expected utility by choosing $c_{t}, h_{t}$ and $k_{t+1}$, subject to the budget constraint, taking prices as given.

- Entrepreneurs decide whether or not to produce. If they do, they choose $H_{i t}$ and $K_{i t}$, to maximize profits, subject to the production technology and the financing constraint, taking prices as given. Firm $i, i \in \Omega_{c t}$ takes as given also the realization of the first idiosyncratic productivity shock, $\varepsilon_{1, i t}$. Firm $i, i \in \Omega_{b t}$ takes as given the realization of $\varepsilon_{1, i t}$ and $\varepsilon_{2, i t}$. Entrepreneurs also choose consumption, $e_{i, t}$, and investment, $z_{i, t+1}$, to maximize their linear utility, subject to their budget constraint.

- FIs and firms solve a CSV problem. The solution determines the amount of external finance to be used and a threshold level for the uncertain productivity factor $\bar{\omega}_{i t}^{j}, j=b, c$. When this factor is lower than the threshold, the firm is monitored.

- The market clearing conditions for goods, labor, capital and loans hold.

A competitive equilibrium is characterized by equations (8)-(12), (17) and (19)-(36). 


\section{Steady state properties: a numerical analysis}

We parameterize the model at the stochastic steady state, which is characterized in Appendix B. The Appendix also describes the numerical procedure used to compute it. We assume that the iid productivity shocks $v=\varepsilon_{1}, \varepsilon_{2}, \varepsilon_{3}$ are $\operatorname{lognormally}$ distributed, i.e. $\log (v)$ is normally distributed with variance $\sigma_{v}^{2}$ and mean $-\sigma_{v}^{2} / 2$. We set the discount factor at $\beta=.98$ and the depreciation rate at $\delta=.025,{ }^{8}$ leading to a real interest rate $r=4 \%$. We choose $\alpha=.64$ in the production function and a coefficient in preferences so that labor equal .3 in steady state, $\eta=2.6$. We set monitoring costs to be $15 \%$ of the firm's output, $\mu=.15$, a value in the middle of the estimates in the empirical literature. ${ }^{9}$ We are then left with 7 free parameters, $\xi, \chi, \tau, \gamma, \sigma_{\varepsilon_{1}}, \sigma_{\varepsilon_{2}}$ and $\sigma_{\varepsilon_{3}}$. In this section we fix them arbitrarily to show the qualitative properties of the model in steady state, i.e. $\xi=1.6, \chi=0, \tau=.11, \gamma=.704$, $\sigma_{\varepsilon_{1}}=.26, \sigma_{\varepsilon_{2}}=.46$ and $\sigma_{\varepsilon_{3}}=.13$. In section 5 below, we calibrate the model and choose the parameters to match stylized facts on the financial structure of the corporate sector in the US and in the euro area (here onwards EA).

In Figure 1, we show expected profits for entrepreneurs. Panel (a) plots respectively expected profits from abstaining, from signing a contract with a bank and from signing a contract with a CMF, as a function of the firm's mark-up, $s=\varepsilon_{1} q$. The intersection points of the three curves provide the cutoff points, $s_{b}$ and $s_{c}$. The panel also shows the mean of the firm-specific mark-up $s$, plus/minus two standard deviations. After the realization of $\varepsilon_{1}, 95 \%$ of the firms' markups lie within this region. Panel (b) shows how expected profits from bank finance move with the information acquisition fee $\tau$. When $\tau=0$, expected profits from bank finance always exceed those from abstaining or from CMF finance. All firms raise external finance through banks. When $\tau$ is large, the option value of acquiring more information is not large enough to offset the cost. All firms either abstain or use CMF finance. Only for intermediate values of $\tau$, firms that decide to produce differentiate in terms of their financing choice. They split into bank finance and CMF finance according to the realization of their markup $s$.

\footnotetext{
${ }^{8}$ The annual depreciation rate is set to equal the US ratio of investment to capital over the period 1964-2001, as reported by Christiano et al (2004).

${ }^{9}$ Warner (1977) estimates small direct costs in a study of 11 railroad bankruptcies, with a maximum of $5.3 \%$ of the firm's value. Altman (1984) finds that direct costs plus indirect costs (those related to the loss of customers, suppliers and employees, and the managerial expenses) are between $12.1 \%$ and $16.7 \%$. Alderson and Betker (1995) provide the largest estimate, $36 \%$ of the firm's value.
} 
Figure 2 illustrates the financial decisions of firms. Panel (a) plots how firms allocate among financial instruments. Conditional on the value of the aggregate variable $q$, firms experiencing a productivity shock $\varepsilon_{1} \leq s_{b} / q$ decide to abstain from production. Firms with $s_{b} / q \leq \varepsilon_{1} \leq s_{c} / q$ sign a contract with banks. Firms with $\varepsilon_{1} \geq s_{c} / q$ sign a contract with CMFs. Among firms that sign a contract with banks, those experiencing a productivity shock $\varepsilon_{2} \leq s_{d} / \varepsilon_{1} q$ decide not to proceed to the production stage. Panel (b) plots the threshold $s_{d} / \varepsilon_{1} q$, over the range of mark-ups $\left(s_{b} / q, s_{c} / q\right)$, as a function of $\varepsilon_{1}$. Panel (c) shows the probability that $\varepsilon_{2} \geq s_{d} / \varepsilon_{1} q$, as a function of $\varepsilon_{1}$. The larger $\varepsilon_{1}$, the lower the threshold level for $\varepsilon_{2}$ and the higher the probability that the firm will produce, conditional on having signed a contract with a bank.

Figure 3 plots the steady state distribution of firms among production activities. Firms that do not produce are those that decide not to raise external finance because $\varepsilon_{1} \leq s_{b} / q$, and those that sign a contract with the bank but, after the realization of $\varepsilon_{2}$, decide to drop out of production. For these firms, $s_{b} / q \leq \varepsilon_{1} \leq s_{c} / q$ and $\varepsilon_{2} \leq s_{d} / q \varepsilon_{1}$.

Figures 4 and 5 plot the results from a sensitivity analysis, which is carried out by modifying one parameter at a time. The first experiment is to look at the effect of different entrepreneurial discount factors by changing the value of $q$. Notice from the steady state version of equation (27) that, for a given level of entrepreneurial effort $\chi$, increasing $q$ is equivalent to increasing the value of $\gamma$. This raises the share of firms that sign a contract with intermediaries and reduces the share of firms that abstain. It also reduces the share of firms that sign a contract with banks relative to CMFs. Intuitively, a higher $q$ increases the firm's expected profits from raising external finance through banks as well as CMFs. However, the higher is $q$, the lower is the option value of waiting that banks provide. Figure 4 illustrates these mechanisms by plotting the shares in steady state as a function of $q$. Panel (a)-(c) reports respectively the share of firms that abstain from production, sign a contract with the bank and sign a contract with the CMF. Panel (d) plots the overall fraction of firms that default and are monitored at the end of the period. For a given $\varepsilon_{1}$, the increase in profits reduces the risk of the firm to default. However, it also induces firms with high risk to undertake productive activities. The overall effect is to increase the realized share of default in the economy for low levels of $q$ and to decrease it afterwards. Finally, panels (e)-(f) plot respectively the share of firms that, after having signed a contract with a bank, abstain or default.

The second experiment, reported in Figure 5, is to change the value of some key parameters, such as $\tau, \sigma_{\varepsilon_{1}}$ and $\sigma_{\varepsilon_{2}}$. In panel (a), we increase the costs of information acquisition, $\tau$, from 
the .11 to .16 , and show with thick lines the new threshold levels, $s_{b} / q$ and $s_{c} / q$. The share of firms that sign a contract with banks decreases and a larger fraction of firms decides to abstain. Panel (b) reports the results from increasing $\sigma_{\varepsilon_{1}}$ from .26 to .46. Firms experience with higher probability low realizations of the productivity shock $\varepsilon_{1}$ before taking their financing decisions. Therefore a larger share of firms decides to abstain. Finally, panel (c) plots the distribution of firms and new thresholds as thick lines, when $\sigma_{\varepsilon_{2}}$ is increased from .46 to .56. With a larger variance of the signal $\sigma_{\varepsilon_{2}}$, firms give a higher value to the possibility to acquire more information through banks. The share of firms that raise bank finance increases.

\section{Comparing the US and the euro area}

In this section, we review the evidence on the financial structure of the corporate sector in the US and the EA. We calibrate the model to capture in steady state some key differences and we provide model-based answers to the questions: What are the causes of differences in the financial structure? What are the implications for allocations?

Some ingredients of our model, such as the degree of heterogeneity of firms in the risk of default or the amount of uncertainty that banks are able to acquire about firms' productivity, cannot be confronted directly with the data because of limited empirical evidence. The calibration procedure described below offers an indirect estimation of those unobserved characteristics of the financial markets based on a structural model.

\subsection{Evidence on intermediation and financial structures}

We document some corporate finance differences between the US and the EA, which we summarize in table 1. Some distinguishing features emerge: the ratio of bank finance to bond finance and the debt to equity ratio are lower in the US than in the EA, while the converse is true for the risk premia on bank loans.

Bank finance to bond finance ratio. We compute the ratio of bank finance to bond finance in the US and in the EA over the period 1997-2003. In the US, the ratio is 0.74. In the EA, it is 7.3, approximately ten times higher. ${ }^{10}$

\footnotetext{
${ }^{10}$ For the US, data are from the Flow of Funds Accounts. Bank finance is given by bank loans plus other loans and advances, i.e. the sum of lines 22 and 23 in Table L 101. Securities are the sum of commercial paper, municipal securities and corporate bonds, lines 19, 20 and 21 in Table L 101. For the euro area, data are from the Euro Area Flow of Funds. Loans are those taken from euro area MFIs and other financial corporations
} 
Debt to equity ratio. The debt to equity ratio for the US non-farm, non-financial corporate business sector is 0.41 over the period 1997-2003. For the EA, the same ratio for non-financial corporations is 0.61 over the period $1997-2002 .^{11}$

Risk premium on bank loans. In the US, the difference between the prime rate on bank loans to business and the commercial paper rate is 298 bps over the period 1997-2003. In the EA, over the same period, the difference between the interest rate on loans up to 1 year of maturity to non-financial corporations and the three-month interest rate, is $267 \mathrm{bps}^{12}$ These numbers should be seen as upper estimates of the existing risk premia. English and Nelson (1998) report selected results from the August 1998 Survey of Terms of Business Lending in the US. The difference between the average loan rate to domestic firms (weighted by loan volumes) and the commercial paper rate emerging from the survey is $188 \mathrm{bps}$, while for the same year the difference between the prime rate and the commercial paper rate is 301 bps. The existence of higher spreads in the US relative to Europe is confirmed by existing studies. Carey and Nini (2004) find that the difference between rates on bank syndicated loans and LIBOR in the US exceeds the corresponding difference in the EMU by 29.8 bps. This finding is supported by calculations of net interest margins in the banking industry by country. Cecchetti (1999) reports interest rate margins for the US in 1996 to be 268 bps. In the same year, the average interest rate margin for Austria, Belgium, Finland, France, Germany, Ireland, Italy, Netherlands, Portugal and Spain is 204.

Risk premium on corporate bonds. In the US, the difference between the average yield to maturity on selected long term corporate bonds (rated Aaa and Baa) minus the 3months Treasury Bill is 339 bps for the period 1997-2003. ${ }^{13}$ English and Nelson (1998) report similar spreads between bank loans rated 1 (best) and 5 (worst) in the 1998 Survey of Terms by non-financial corporations. Securities are defined as securities other than shares issued by non-financial corporations.

${ }^{11}$ For the US, data are from the Flow of Funds Accounts. Debt is defined as credit market instruments (sum of commercial paper, municipal securities, corporate bonds, bank loans, other loans and advances, mortgages) over the market value of equities outstanding (including corporate farm equities), Table B.102. Masulis (1988) reports a ratio of debt to equity for US corporations in the range 0.5-0.75 for the period 1937-1984. The ratio exhibited a downward trend over the last decades due to financial innovations. For the euro area, data are from the Euro area Flow of Funds. Debt includes loans, debt securities issued and pension fund reserves of non-financial corporations. Equity includes quoted and non-quoted equity.

${ }^{12}$ Source: for the US, Federal Resrve Board, Table H15; for the euro area, European Central Bank, MU12 average based on country reporting to BIS.

${ }^{13}$ Source: Federal Reserve Board, Table H15. 
of Business Lending, and between yields on AA rated bonds and 'junk' bonds covered in the same survey. The spreads reported are around 200 bps. Mahajan and Fraser (1986) find no evidence of differences among bond spreads in the US and the EA. Using more recent data, Carey and Nini (2004) examine spreads estimated using daily Merrill Lynch bond index yields and swap data for the period 1999-2003 for A- and BBB-rated firms. They find only small mean and median differences between US and EA, after accounting for duration and currency effects. $^{14}$

Default rates. Carlstrom and Fuerst (1997) report average annual default rates from the Dun and Bradstreet data set of 3.9\%. Bernanke, Gertler and Gilchrist (1999) compute the average annual firms failures in the post World War II period at 3\%. Default rates for high risk corporate bonds are not too different from the average figures. Helwege and Kleiman (1996) find an average annual default rate for all high yield bond issuers of $4.5 \%$ over the period 1981-1995. Ammer and Packer (2000) compare default rates of US and foreign non-financial corporations. They examine bonds of 492 issuers present in Moody's database over the period 1983-1988 and find that the average annual default rate by type of issuer is higher for US non-financial corporations than for foreign firms. However, after controlling for the rating composition of each sectorial pool, default rates for US and foreign firms are similar.

Table 1: Summary of financial facts

\begin{tabular}{|l|l|l|}
\hline Variable & US data & EA data \\
\hline Bank to bond finance & 0.74 & 7.3 \\
\hline Debt to equity & 0.41 & 0.61 \\
\hline Risk premium bonds & $0.019-0.034$ & as in US \\
\hline Risk premium loans & $0.019-0.030$ & $0.016-0.027$ \\
\hline Average default rate & $0.030-0.045$ & as in US \\
\hline
\end{tabular}

\footnotetext{
${ }^{14}$ Our model assumes no fixed cost of issuance of corporate bonds. Santos and Tsatsaronis (2003) use the IFR Platinum database compiled by Thomson Financial Studies, which covers 3,110 bonds issued by the private sector between 1994 and 2001. They find that average gross issuance fees over the period considered are small: $0.82 \%$ of the amount raised for bonds issued in US dollars and $0.89 \%$ for bonds issued in euros. Given the size of these fees and the similarity among US and euro area, we abstract from them in our analysis.
} 


\subsection{Calibration}

We set $\alpha, \delta, \beta$ and $\mu$ at the values described in section 5.1 and $\eta$ such that $l=.3$ in steady state both for the US model and the EA model. We are then left with seven free parameters, $\xi, \tau, \gamma, \chi, \sigma_{\varepsilon_{1}}, \sigma_{\varepsilon_{2}}$ and $\sigma_{\varepsilon_{3}}$. The calibration procedure selects the value of $\gamma$ to minimize the squared log-deviation of the entrepreneur's from the household's discount factor and the remaining parameters to minimize the squared log-deviation of the model steady state values from the empirical counterparts for the ratio of bank finance to bond finance, the debt to equity ratio, the average default rate, the risk premium on bonds, the risk premium on loans and the investment to GDP ratio. ${ }^{15}$

Notice that the data show marked corporate finance differences between the US and the EA but rather homogeneous investment to GDP ratios. ${ }^{16}$ In the model, the existence of entrepreneurial effort allows to disentangle the entrepreneurs' financing decisions from their investment decisions. The calibration procedure aims at matching corporate finance differences without introducing counterfactual discrepancies in the investment to GDP ratio or implausible degrees of entrepreneurial patience. The selected parameter values are reported in table 2 .

Table 2: Parameter values

\begin{tabular}{|l|l|l|}
\hline Parameters & US model & EA model \\
\hline$\tau$ & 0.059 & 0.134 \\
\hline$\chi$ & 0.421 & 0.069 \\
\hline$\gamma$ & 0.928 & 0.757 \\
\hline$\xi$ & 1.410 & 1.610 \\
\hline$\sigma_{\varepsilon_{1}}$ & 0.054 & 0.012 \\
\hline$\sigma_{\varepsilon_{2}}$ & 0.131 & 0.429 \\
\hline$\sigma_{\varepsilon_{3}}$ & 0.645 & 0.576 \\
\hline
\end{tabular}

Table 3 evaluates the performance of the calibrated model in terms of the financial facts outlined above. The model is able to capture large part of the difference in the ratio of bank

\footnotetext{
${ }^{15}$ See Appendix B for further details on the calibration procedure.

${ }^{16}$ Over the period 1999-2004, the ratio of gross fixed capital formation to GDP has been similar in the two blocks, being .192 in the US and .206 in the euro area. Source: European Central Bank.
} 
finance to bond finance of the US and the EA, while matching the difference in the debt to equity ratio. The model also delivers reasonable risk premia and default rates, although in the EA the risk premium on bonds is slightly below the level observed in the data.

Table 3: Financial facts

\begin{tabular}{|l|l|l|l|l|}
\hline Variable & US model & US data & EA model & EA data \\
\hline Bank to bond finance & 0.856 & 0.740 & 4.163 & 7.300 \\
\hline Debt to equity & 0.410 & 0.410 & 0.610 & 0.610 \\
\hline Risk premium on bonds & 0.028 & $0.019-0.034$ & 0.013 & $0.019-0.034$ \\
\hline Risk premium on loans & 0.022 & $0.019-0.030$ & 0.022 & $0.016-0.027$ \\
\hline Average default rate & 0.041 & $0.030-0.045$ & 0.047 & $0.030-0.045$ \\
\hline
\end{tabular}

Other predictions of the model in steady state are documented in table 4. Some distinguishing features emerge in the US and EA models under our preferred calibration. First, in the EA model all firms approach a financial intermediary. Given the limited amount of observable heterogeneity $\left(\sigma_{\varepsilon_{1}}\right)$, firms prefer to approach a bank and to acquire further information before deciding whether or not to produce. In the US model, where the degree of ex-ante heterogeneity is larger, 10 percent of the firms decide to abstain from production and not to approach a financial intermediary. On the contrary, the share of firms that drop-out from production conditional on having approached a bank (reported in the fifth row) is similar in the two blocks, reflecting the standard deviation of the relevant uncertain productivity factor $\left(\sigma_{\varepsilon_{3}}\right)$. In terms of allocations, the two models delivers similar investment to GDP ratios in the US and in the EA. ${ }^{17}$ Higher agency costs in the EA relative to the US leave a relatively lower amount of resources available for private consumption. Finally, the value of the aggregate mark-up, $q$, is larger in the model of the US than in the model of the EA.

\footnotetext{
${ }^{17}$ The investment to GDP ratios predicted by the model should not be compared directly to those observed in the data, given the absence of a public sector.
} 
Table 4: Model predictions

\begin{tabular}{|l|l|l|}
\hline Variable & US & EA \\
\hline Share abstain & 0.104 & 0.000 \\
\hline Share bank & 0.579 & 0.885 \\
\hline Share CMF & 0.317 & 0.115 \\
\hline Drop-out if banking & 0.509 & 0.437 \\
\hline$q$ & 1.471 & 1.297 \\
\hline$\frac{c+e}{y}$ & 0.826 & 0.761 \\
\hline$\frac{I}{y}$ & 0.127 & 0.124 \\
\hline$\frac{y^{a}}{y}$ & 0.047 & 0.116 \\
\hline
\end{tabular}

To provide a better understanding of the calibrated models, we carry out a sensitivity analysis. We change one parameter at a time in the EA model, fix it to the same value of the US model and compare the model predictions to those arising under our benchmark calibration. The results are shown in table 5. The second and third column report the predictions of the benchmark US and EA models to facilitate the comparison. The fourth column reports the results when $\chi=.421$, as in the US model, and all other parameters are unchanged. The larger entrepreneurial effort reduces expected utility from entrepreneurial activity and increases the option value of banking. Given the low degree of ex-ante heterogeneity in the EA, entrepreneurs choose to approach a bank because this allows them to acquire further information before deciding whether to incur the large disutility arising from production. The fifth column shows the results when $\tau$ is fixed at .059. For given uncertainty about the shock $\varepsilon_{2}$, such a low $\tau$ increases expected payoff from bank finance to the point where all firms choose to approach banks. The sixth column lists the results when $\sigma_{\varepsilon_{1}}$ is fixed at .054. The higher degree of ex-ante heterogeneity among firms reduces the value of flexibility provided by banks. A larger share of firms chooses CMF finance. Finally, the last column reports the case when $\sigma_{\varepsilon_{3}}=.645$. This higher value has two effects. On the one hand, it reduces the relative gain from information acquisition about $\varepsilon_{2}$, thus lowering the share of firms choosing to approach banks. Second, it increases the overall uncertainty in the economy. Risk premia and the average default rate increase sizably. 
Table 5: Sensitivity analysis

\begin{tabular}{|l|l|l|l|l|l|l|}
\hline Variable & US & EA & \multicolumn{1}{|c|}{$\begin{array}{c}\text { EA } \\
\chi=.421\end{array}$} & $\begin{array}{c}\text { EA } \\
\tau=.059\end{array}$ & \multicolumn{1}{|c|}{$\begin{array}{c}\text { EA } \\
\sigma_{\varepsilon_{1}}=.054\end{array}$} & \multicolumn{1}{|c|}{$\sigma_{\varepsilon_{3}}=.645$} \\
\hline Bank to bond finance & 0.856 & 4.163 & $\rightarrow \infty$ & $\rightarrow \infty$ & 0.780 & 0.645 \\
\hline Debt to equity & 0.410 & 0.610 & 0.610 & 0.610 & 0.610 & 0.610 \\
\hline Risk premium on bonds & 0.028 & 0.013 & 0.000 & 0.000 & 0.042 & 0.054 \\
\hline Risk premium on loans & 0.022 & 0.022 & 0.013 & 0.025 & 0.015 & 0.023 \\
\hline Average default rate & 0.041 & 0.047 & 0.006 & 0.026 & 0.029 & 0.149 \\
\hline Share abstain & 0.104 & 0.000 & 0.000 & 0.000 & 0.000 & 0.000 \\
\hline Share bank & 0.579 & 0.885 & 1.000 & 1.000 & 0.621 & 0.516 \\
\hline Share CMF & 0.317 & 0.115 & 0.000 & 0.000 & 0.379 & 0.484 \\
\hline Drop-out if banking & 0.509 & 0.437 & 0.669 & 0.430 & 0.460 & 0.442 \\
\hline$q$ & 1.471 & 1.297 & 1.292 & 1.292 & 1.292 & 1.292 \\
\hline$\frac{c+e}{y}$ & 0.826 & 0.761 & 0.727 & 0.809 & 0.789 & 0.787 \\
\hline$\frac{I}{y}$ & 0.127 & 0.124 & 0.107 & 0.121 & 0.135 & 0.138 \\
\hline$\frac{y^{a}}{y}$ & 0.047 & 0.116 & 0.165 & 0.069 & 0.076 & 0.075 \\
\hline
\end{tabular}

We also carry out a model comparison by fixing some parameters in the EA model at the values set in the benchmark US model, and by searching for values of the remaining parameters that provide the best fit according to the seven criteria described above. Table 6 shows the new parameters in the last three columns and compare them to the preferred ones, which are reported for convenience in the second and third columns. The table lists in bold the parameters fixed at the level set in the US model and in normal font the newly optimized coefficients. The fourth column shows the case where the standard deviation of the shock that is public knowledge, $\sigma_{\varepsilon_{1}}$, is fixed. The fifth column shows the case when both $\sigma_{\varepsilon_{1}}$ and the information acquisition cost per unit of net worth, $\tau$, are fixed at the US values. Finally, the last column reports the values when $\sigma_{\varepsilon_{1}}, \sigma_{\varepsilon_{2}}$ and $\tau$ are fixed. Notice that this case corresponds to constraining the degree of ex-ante heterogeneity and the relative efficiency of banks in the EA to the US values. In fact, $\frac{\sigma_{\varepsilon_{2}}}{\tau}$ can be seen as a measure of overall efficiency of banks in providing information to the market. For a given information acquisition fee $\tau$, banks are more efficient if they are able to disclose information about a more volatile shock, i.e. if $\frac{\sigma_{\varepsilon_{2}}}{\tau}$ is higher. 
Table 6: Parametric restrictions

\begin{tabular}{|l|l|l|l|l|l|}
\hline Parameters & US & EA & EA I & EA II & EA III \\
\hline$\tau$ & 0.059 & 0.134 & 0.106 & $\mathbf{0 . 0 5 9}$ & $\mathbf{0 . 0 5 9}$ \\
\hline$\chi$ & 0.421 & 0.069 & 0.038 & 0.027 & 0.184 \\
\hline$\gamma$ & 0.928 & 0.757 & 0.779 & 0.751 & 0.963 \\
\hline$\xi$ & 1.410 & 1.610 & 1.610 & 1.610 & 1.610 \\
\hline$\sigma_{\varepsilon_{1}}$ & 0.054 & 0.012 & $\mathbf{0 . 0 5 4}$ & $\mathbf{0 . 0 5 4}$ & $\mathbf{0 . 0 5 4}$ \\
\hline$\sigma_{\varepsilon_{2}}$ & 0.131 & 0.429 & 0.382 & 0.296 & $\mathbf{0 . 1 3 1}$ \\
\hline$\sigma_{\varepsilon_{3}}$ & 0.645 & 0.576 & 0.592 & 0.600 & 0.693 \\
\hline$\frac{\sigma_{\varepsilon_{2}}}{\tau}$ & 2.220 & 3.201 & 3.603 & 5.017 & 2.220 \\
\hline
\end{tabular}

Model predictions under each parameterization are reported in table 7. Columns four to six mark in bold those facts where the fit is worse than for the benchmark EA model. Model EA I delivers predictions similar to those obtained under the benchmark EA model. Interestingly, the value of the standard deviation of the first shock, $\sigma_{\varepsilon_{1}}$, has no major implications for the fit of the model. On the contrary, the calibration procedure for EA II introduces a discrepancy between the investment to GDP ratio of the EA and of the US. Model EA II also overestimates the risk premium on loans and the average default rate, while it underestimates to a larger degree the risk premium on bonds. Under model EA III, the fit of the model deteriorates further. The predicted risk premium on loans is higher and the premium on bonds is lower than in the benchmark model. More crucially, the model matches to a lower extent the observed difference in the ratio of bank finance to bond finance.

\subsubsection{Explaining differences in financial structures}

Under our benchmark calibration, substantial differences arise in the parameter values of the US and EA models. The values reported in table 2 can help explain existing differences in the financial structure of the two blocks.

First, the calibrated models suggest that the overall uncertainty about the unobserved productivity shocks $\left(\sigma_{\varepsilon_{2}}+\sigma_{\varepsilon_{3}}\right)$ is lower in the US (.78) than in the EA (1.0). Moreover, the 
Table 7: Model predictions

\begin{tabular}{|l|l|l|l|l|l|}
\hline Variable & US & EA & EA I & EA II & EA III \\
\hline Bank to bond finance & 0.860 & 4.100 & 4.105 & 4.021 & $\mathbf{2 . 9 4 6}$ \\
\hline Debt to equity & 0.410 & 0.610 & 0.610 & 0.610 & 0.610 \\
\hline Risk premium bonds & 0.028 & 0.013 & 0.013 & $\mathbf{0 . 0 1 2}$ & $\mathbf{0 . 0 1 1}$ \\
\hline Risk premium loans & 0.022 & 0.022 & 0.024 & $\mathbf{0 . 0 2 8}$ & $\mathbf{0 . 0 2 8}$ \\
\hline Average default rate & 0.041 & 0.047 & 0.048 & $\mathbf{0 . 0 6 0}$ & 0.044 \\
\hline Share abstain & 0.104 & 0.000 & 0.000 & 0.000 & 0.303 \\
\hline Share bank & 0.579 & 0.885 & 0.893 & 0.870 & 0.606 \\
\hline Share CMF & 0.317 & 0.115 & 0.107 & 0.130 & 0.091 \\
\hline Drop-out if banking & 0.509 & 0.437 & 0.452 & 0.369 & 0.546 \\
\hline$q$ & 0.047 & 1.297 & 1.219 & 1.240 & 1.196 \\
\hline$\frac{c+e}{y}$ & 0.826 & 0.761 & 0.768 & 0.804 & 0.779 \\
\hline$\frac{I}{y}$ & 0.826 & 0.124 & 0.133 & $\mathbf{0 . 1 4 0}$ & $\mathbf{0 . 1 5 0}$ \\
\hline$\frac{y^{a}}{y}$ & 0.127 & 0.116 & 0.099 & 0.056 & 0.071 \\
\hline
\end{tabular}

composition of the overall uncertainty is different. The shock $\varepsilon_{2}$, which can only be observed through bank relationship and information acquisition, is relatively more volatile in the EA than in the US, while the standard deviation of the productivity factor $\varepsilon_{1}$, which is known to firms at the time of their financing decisions, is larger in the US (.054) than in the EA (.012). This is also true for the standard deviation of the first idiosyncratic shock relative to the standard deviation of the overall uncertain productivity factor, $\sigma_{\varepsilon_{1}} /\left(\sigma_{\varepsilon_{2}}+\sigma_{\varepsilon_{3}}\right)$, which takes the value of .07 for the US and .01 for the EA. Finally, notice that in the calibrated model of the EA, banks are able to disclose substantially more information about firms than in the model of the US. The signal-to-variance ratio $\sigma_{\varepsilon_{2}}^{2} /\left(\sigma_{\varepsilon_{2}}^{2}+\sigma_{\varepsilon_{3}}^{2}\right)$ takes the value of .36 in the EA and only .04 in the US. This is counteracted by higher information acquisition costs in the EA relative to the US, $\tau$ being respectively .134 and .059. However, the measure of overall efficiency of banks in acquiring information about firms, $\frac{\sigma_{\varepsilon_{2}}}{\tau}$, equals 2.2 for the US and 3.6 for the EA, suggesting relatively higher efficiency of european banks.

Notice that $\sigma_{\varepsilon_{1}}$ provides a measure of public information available in the financial market, i.e. the information known to firms and FIs before signing the contract. A larger $\sigma_{\varepsilon_{1}}$ allows FIs to better discriminate firms according to their risk. Credit worthy firms are those that, 
having experienced a high realization of the first shock, face a relatively low risk of default at the end of the period. On the other hand, $\sigma_{\varepsilon_{2}}$ provides a measure of the amount of private information, which is costly to acquire and can only be obtained by banks.

Overall, the model suggests that the flexibility provided by banks and their information acquisition role is more valuable for firms in the EA than in the US. Moreover, the model points to a relatively higher efficiency of banking services in the EA. These factors provide a major explanation for the larger role of bank finance relative to bond finance in the EA.

\subsubsection{Effects of differences in financial structures on allocations}

To assess the quantitative importance of the financial structure for the macroeconomy, we build two alternative versions of the model described above and calibrate them on US data. The versions we consider capture financial differences to various extents.

Alternative I. This is a model with no ex-ante heterogeneity and a single type of FI, as in Carlstrom and Fuerst (2001). It is obtained by setting $\tau, \sigma_{\varepsilon_{1}}$ and $\sigma_{\varepsilon_{2}}$ close to zero. ${ }^{18}$ The parameter $\xi$ is chosen to replicate the firm's debt to equity ratio, while $\gamma, \sigma_{\varepsilon_{3}}$ and $\chi$ are set to replicate the aggregate default rates, average risk premia and investment to GDP ratios predicted by the benchmark US model.

Alternative II. This is a model with ex-ante heterogeneity and a single type of FI. It is built by setting $\tau$ and $\sigma_{\varepsilon_{2}}$ close to zero, in which case no firm chooses to raise bank finance. The parameter $\xi$ is chosen to match the firm's debt to equity ratio, while $\gamma, \sigma_{\varepsilon_{3}}$ and $\chi$ are set to replicate the aggregate default rates, average risk premia and investment to GDP ratios predicted by the benchmark US model. Finally, $\sigma_{\varepsilon_{1}}$ is set to the same value obtained in the benchmark US model.

Table 8 lists the parameters selected for the two alternative versions and compare them with those of our benchmark model (reported in the last column).

Table 9 compares the predictions of the three model versions for the US. In model US I, with no heterogeneity and one instrument of external finance, all firms produce and raise finance from CMFs. To match the financial facts, the calibration procedure selects lower

\footnotetext{
${ }^{18}$ The values are not exactly zero because, when $\tau=\sigma_{\varepsilon_{1}}=\sigma_{\varepsilon_{2}}=0$, expected utility from producing using CMF finance or bank finance are identical. The numerical procedure is then unable to solve for the thresholds $s_{b}, s_{c}$ and $s_{d}$.
} 
entrepreneurial effort, $\chi$, and lower standard deviation of the unobserved shock, $\sigma_{\varepsilon_{3}}$, than in model US II and in the benchmark US model. The reason is that a positive $\sigma_{\varepsilon_{1}}$ corresponds to higher disclosure of public information in the financial market, which allows FIs to discriminate firms according to their risk. In this case, a larger $\sigma_{\varepsilon_{3}}$ is needed to generate the observed average risk premia and default rates. A lower entrepreneurial effort is needed to generate the same investment to GDP ratio, because expected returns from production change due to the lower standard deviation of the unobserved productivity factor.

Table 8: Parameter values in alternative versions of the model

\begin{tabular}{|l|l|l|l|}
\hline Parameters & model US I & model US II & model US \\
\hline$\tau$ & 0.006 & 0.006 & 0.059 \\
\hline$\chi$ & 0.338 & 0.380 & 0.421 \\
\hline$\gamma$ & 0.968 & 0.920 & 0.928 \\
\hline$\xi$ & 1.410 & 1.410 & 1.410 \\
\hline$\sigma_{\varepsilon_{1}}$ & 0.006 & 0.054 & 0.054 \\
\hline$\sigma_{\varepsilon_{2}}$ & 0.006 & 0.006 & 0.131 \\
\hline$\sigma_{\varepsilon_{3}}$ & 0.550 & 0.600 & 0.645 \\
\hline
\end{tabular}

Notice that the introduction of ex-ante heterogeneity without the possibility of using alternative instruments of external finance, as in model US II, has minor effects on the shares of consumption, investment and monitoring costs in output. The model with ex-ante heterogeneity experiences a higher per-capita GDP, since the availability of public information allows firms to assess ex-ante their risk of default and possibly to abstain from production. The average risk premium charged by FIs to producing firms is thus lower, despite the higher default rates reflecting the larger standard deviation of the overall uncertain productivity factor. Thus, per-capita GDP rises, though to a limited extent.

The combination of ex-ante heterogeneity and multiple instruments of external finance has larger effects on allocations. When two instruments of external finance are available, a higher share of firms decides to approach a FI. By choosing banks, firms with high risk of default can acquire information about the uncertain productivity factor, postponing their decision 
on whether or not to borrow and produce. The average risk premium falls and production increases further.

Table 9: Alternative models and their predictions

\begin{tabular}{|l|l|l|l|}
\hline Variable & model US I & model US II & model US \\
\hline Bank to bond finance & 0 & 0 & 0.86 \\
\hline Debt to equity & 0.41 & 0.41 & 0.41 \\
\hline Average risk premium & 0.030 & 0.026 & 0.025 \\
\hline Average default rate & 0.035 & 0.040 & 0.046 \\
\hline Share abstain & 0.000 & 0.283 & 0.104 \\
\hline Share bank & 0 & 0 & 0.579 \\
\hline Share CMF & 1.000 & 0.717 & 0.317 \\
\hline Drop-out if banking & 0 & 0 & 0.509 \\
\hline$q$ & 1.370 & 1.440 & 1.470 \\
\hline$\frac{c+e}{y}$ & 0.848 & 0.850 & 0.826 \\
\hline$\frac{I}{y}$ & 0.145 & 0.134 & 0.127 \\
\hline$\frac{y^{a}}{y}$ & 0.007 & 0.015 & 0.050 \\
\hline$y$ & 0.838 & 0.842 & 0.867 \\
\hline
\end{tabular}

Table 10 shows the gap in per-capita GDP that emerges in models with different financial structures. The second row computes the ratio between output from model II and model I, where the only difference is the presence of ex-ante heterogeneity. The gap is only 0.5 percentage points. The third row compares the ratio between output from the benchmark model and model II, which share the same degree of ex-ante heterogeneity but differ in the availability of the instruments of external finance. The gap rises to 3 percentage points. The last row shows the ratio between output from the benchmark model and model I, which differ both in the presence of ex-ante heterogeneity and in the availability of two instruments of external finance. The combined effects is a gap of 3.5 percentage points. 
Table 10: Financial structure and per-capita GDP

\begin{tabular}{|l|l|}
\hline Differences in financial structure & Output ratio \\
\hline ex-ante heterogeneity & $\frac{y_{(I I)}}{y_{(I)}}=1.005$ \\
\hline two instruments of external finance & $\frac{y}{y_{(I I)}}=1.030$ \\
\hline \multicolumn{2}{|c|}{ ex-ante heterogeneity } \\
two instruments of external finance
\end{tabular}

\section{Conclusions}

We have presented a dynamic general equilibrium model with agency costs, ex-ante firms' heterogeneity and multiple instruments of external finance. In this economy, the choice of entrepreneurs among alternative financing instruments determines the overall cost of information asymmetries and credit market frictions. The calibrated model suggests that a larger share of bank finance in the EA relative to the US is due to lower availability of public information about firms' credit worthiness and to higher efficiency of banks in acquiring this type of information. We also find that differences in the financial structure affect allocations, leading to non negligible discrepancies in per-capita GDP.

The setup presented in this paper can be extended in various directions. In ongoing research, we develop a monetary dynamic general equilibrium model of the financial structure and ask whether it can replicate the differences in the transmission of monetary policy observed in the US and the EA (as documented, for instance, by Angeloni et al (2003)). Information on financial structures is typically regarded as important by central banks. Movements in the policy rate influence market interest rates, the price of financial assets, and real activity through changes in the financial decisions of consumers and investors. Features of the financial system such as the relative importance of bank loans versus other instruments of external finance may thus help to explain differences in the transmission of monetary policy.

\section{Appendix}

\section{A. Cross-state subsidization}

We consider a general class of contracts between banks and firms, which specify the threshold level $\bar{\omega}\left(s \varepsilon_{2}\right)$ and the up-front fee $c\left(s \varepsilon_{2}\right)$ that, given $s=\varepsilon_{1} q$, maximize the firm's expected 
return across realizations of $\varepsilon_{2}$, subject to the project size being a fixed share of the firm's net worth, the feasibility constraint, the bank breaking even in expectations across states, the sum of all repayments across firms covering the information costs faced by the bank, and the up-front fee not exceeding the available initial net worth.

The optimal contract is given by the pair $\left[\bar{\omega}^{b}\left(s \varepsilon_{2}\right), c\left(s \varepsilon_{2}\right)\right]$ that solves the problem

$$
\max _{c\left(s \varepsilon_{2}\right), \bar{\omega}^{b}\left(s \varepsilon_{2}\right)} \int_{\frac{s_{d}}{s}} s \varepsilon_{2} f\left(\bar{\omega}^{b}\left(s \varepsilon_{2}\right)\right)\left(1-c\left(s \varepsilon_{2}\right)\right) \zeta \Phi_{2}\left(d \varepsilon_{2}\right)+\int^{\frac{s_{d}}{s}}\left(1-c\left(s \varepsilon_{2}\right)\right) \Phi_{2}\left(d \varepsilon_{2}\right)
$$

subject to constraint (7), (15) and

$$
\begin{gathered}
\int_{\frac{s_{d}}{s}} s \varepsilon_{2} g\left(\bar{\omega}^{b}\left(s \varepsilon_{2}\right)\right)\left(1-c\left(s \varepsilon_{2}\right)\right) \zeta \Phi_{2}\left(d \varepsilon_{2}\right)+\int^{\frac{s_{d}}{s}} c\left(s \varepsilon_{2}\right) \Phi_{2}\left(d \varepsilon_{2}\right) \\
\geq \int_{\frac{s_{d}}{s}}\left(1-c\left(s \varepsilon_{2}\right)\right)(\zeta-1) \Phi_{2}\left(d \varepsilon_{2}\right)+\tau \\
\int c\left(s \varepsilon_{2}\right) \Phi_{2}\left(d \varepsilon_{2}\right) \geq \tau \\
c\left(s \varepsilon_{2}\right) \leq 1 \text { for all } \varepsilon_{2} .
\end{gathered}
$$

Denote as $\lambda(s), \theta(s)$ and $\eta\left(s \varepsilon_{2}\right)$ the Lagrangian multipliers on constraints (37), (38) and (39) respectively. The first order condition with respect to $\bar{\omega}^{b}\left(s \varepsilon_{2}\right)$ is given by

$$
s \varepsilon_{2}\left\{f^{\prime}\left(\bar{\omega}^{b}\left(s \varepsilon_{2}\right)\right)-\lambda(s)\left[f^{\prime}\left(\bar{\omega}^{b}\left(s \varepsilon_{2}\right)\right)+\mu \phi\left(\bar{\omega}^{b}\left(s \varepsilon_{2}\right)\right)\right]\right\}\left(1-c\left(s \varepsilon_{2}\right)\right) \zeta \leq 0, \quad \text { if } \varepsilon_{2} \geq \frac{s_{d}}{s} .
$$

The conditions with respect to $c\left(s \varepsilon_{2}\right)$ are given by

$$
\begin{gathered}
-s \varepsilon_{2} f\left(\bar{\omega}^{b}\left(s \varepsilon_{2}\right)\right) \zeta+\lambda(s)\left\{-s \varepsilon_{2} g\left(\bar{\omega}^{b}\left(s \varepsilon_{2}\right)\right) \zeta+\zeta-1\right\}+\theta(s)-\eta\left(s \varepsilon_{2}\right) \leq 0, \quad \text { if } \varepsilon_{2} \geq \frac{s_{d}}{s} \\
-1+\lambda(s)+\theta(s)-\eta\left(s \varepsilon_{2}\right) \leq 0, \text { if } \varepsilon_{2}<\frac{s_{d}}{s} .
\end{gathered}
$$

The first two constraints of the FI are binding at the optimum. Therefore, $\lambda(s)$ and $\theta(s)$ must be strictly positive. Notice also that condition (40) implies that at the optimum, when monitoring costs are not zero,

$$
\lambda(s)=\frac{f^{\prime}\left(\bar{\omega}^{b}\left(s \varepsilon_{2}\right)\right)}{f^{\prime}\left(\bar{\omega}^{b}\left(s \varepsilon_{2}\right)\right)+\mu \phi\left(\bar{\omega}^{b}\left(s \varepsilon_{2}\right)\right)}>1,
$$

since $f^{\prime}\left(\bar{\omega}^{b}\right)<0$ and $g^{\prime}\left(\bar{\omega}^{b}\right)>0$. It follows that $\theta(s)+\lambda(s)-1 \geq 0$, and optimality requires that $\eta\left(s \varepsilon_{2}\right)=\bar{\eta}(s)>0$ or

$$
c\left(s \varepsilon_{2}\right)=1, \text { if } \varepsilon_{2}<\frac{s_{d}}{s} .
$$


Hence, the contract is given by an up-front fee of $100 \%$ of the initial net worth, if the firm does not produce, and by a threshold for the unobserved shock $\bar{\omega}^{b}\left(s \varepsilon_{2}\right)$ and an up-front fee $c\left(s \varepsilon_{2}\right)$ that satisfy (40) and (41), if the firm undertakes production. Notice that the threshold $\bar{\omega}^{b}$ is contingent on $s$ and on the realization of the observed shock $\varepsilon_{2}$, but it does not depend on the realization of the unknown productivity shock, $\varepsilon_{3}$. Hence, firms have no incentive to mis-report the realization of the shock that cannot be observed by the bank.

The contract is optimal. The bank now uses the net worth of non-producing firms to provide part of the external finance, at no cost, to producing firms. Repayments are minimized and so is the aggregate probability of default and expected monitoring costs. This increases the fraction of output accruing to the entrepreneurs and hence their aggregate consumption. Since entrepreneurs are risk-neutral, cross-subsidization enhances their welfare.

\section{B. The stochastic steady state}

We denote steady state variables by dropping the time subscript. The unique steady state can be obtained as follows. First, we find it convenient to specify one of the endogenous variables, $q$, as exogenous and to treat $\gamma$ as endogenous. For each value of $q$, we can then compute $r, w, \gamma$ and $c$ by solving the equations

$$
\begin{aligned}
1 & =\beta(1-\delta+r) \\
q & =\left(\frac{\alpha}{w}\right)^{\alpha}\left(\frac{1-\alpha}{r}\right)^{1-\alpha} \\
1 & =\beta \gamma\left\{(1-\delta+r) F\left(\varepsilon_{1} q\right)\right\} \\
\eta c & =w .
\end{aligned}
$$

To compute the overall expected profits $F\left(\varepsilon_{1} q\right)$, given by the steady state version of (27), we use the following procedure. First, under our distributional assumptions about the productivity shocks $\varepsilon_{1}, \varepsilon_{2}$ and $\varepsilon_{3}$, we can use some results from the optimal contract literature (see the appendix of Bernanke et al (1999)),

$$
\begin{gathered}
\varphi_{\omega}\left(\bar{\omega}^{j}\right)=\varphi(x) \frac{1}{\bar{\omega}^{j} \sigma} \\
f\left(\bar{\omega}^{j}\right)=1-\Phi(x-\sigma)-\bar{\omega}^{j}[1-\Phi(x)] \\
g\left(\bar{\omega}^{j}\right)=\Phi(x-\sigma)+\bar{\omega}^{j}-\left(\bar{\omega}^{j}+\mu\right) \Phi(x),
\end{gathered}
$$

where $\varphi$ and $\Phi$ denote the standard normal, $x \equiv \frac{\log \bar{\omega}^{j}+0.5 \sigma^{2}}{\sigma}$ and $j=b, c$. Second, we solve numerically the condition $s g\left(\bar{\omega}^{j}(s)\right)=\frac{\xi-1}{\xi}$ to obtain the function $\bar{\omega}^{j}(s)$. The function $\bar{\omega}^{b}(s)$ 
for bank-financed firms is derived by defining $s=\varepsilon_{1} \varepsilon_{2} q$ and by using the variance $\sigma_{\varepsilon_{3}}^{2}$ of the log-normal distribution. The function $\bar{\omega}^{c}(s)$ for CMF-financed firms is derived by defining $s=\varepsilon_{1} q$ and by using the variance $\sigma_{\varepsilon_{2}}^{2}+\sigma_{\varepsilon_{3}}^{2}$. The cutoff value for proceeding with the bank loan is found by solving numerically the condition $\left[s_{d} f\left(\bar{\omega}^{b}\left(s_{d}\right)\right)-\chi\right] \xi=1$. Using $s_{d}$, it is then possible to compute the expected utility for the bank-financed entrepreneur, $F^{b}(s)$, where $s=\varepsilon_{1} q$. The expected utility for the CMF-financed entrepreneur can be computed as $F^{c}(s)=$ $\left[s f\left(\bar{\omega}^{c}(s)\right)-\chi\right] \xi$. With this, it is possible to calculate the overall return $F(s)$ to entrepreneurial investment, the thresholds $s_{b}$ and $s_{c}$, and the ratios $\frac{x}{z}, \frac{K}{x}$ and $\frac{l}{x}$, as given by

$$
\begin{gathered}
\frac{x}{z}=\psi^{x}\left(q ; s_{b}, s_{c}, s_{d}\right) \xi(1-\delta+r) \\
\frac{K}{x}=\frac{1-\alpha}{r} \\
\frac{l}{x}=\frac{\alpha}{w},
\end{gathered}
$$

where the function $\psi^{x}(\cdot)$ is the steady state version of the function defined in Appendix C. Now write the budget constraint of the household as

$$
\frac{c}{z}=w \frac{l}{z}+(r-\delta) \frac{k}{z}
$$

where

$$
\frac{l}{z}=\frac{l}{x} \frac{x}{z}
$$

and

$$
\frac{k}{z}=\frac{K}{x} \frac{x}{z}-1
$$

Then, compute $z$ as $z=\frac{c}{\frac{c}{z}}$ and use it to compute the aggregate variables $n, x, K, l, k$ and $c$. Finally, use the steady state version of equations (29) and (31) to compute $y$ and $e$, and of the resource constraint (36) to compute $y^{a}$.

The calibration procedure selects values for $\xi, \tau, \gamma, \chi, \sigma_{\varepsilon_{1}}, \sigma_{\varepsilon_{2}}, \sigma_{\varepsilon_{3}}$ that minimize the squared log-deviation of the first moments generated by the model from those obtained in the data. In the US model, the targets for the debt to equity ratio, the ratio of bank to bond finance, the average annual default rate, the risk premium on bonds, the risk premium on loans, the investment to output ratio and the parameter $\gamma$ are respectively $.41, .75, .039, .027, .025, .192$ and .97. In the model of the EA, the targets for the investment to GDP ratio and for $\gamma$ are provided by the values obtained in the calibrated model of the US. The targets for the debt to equity ratio, the ratio of bank finance to bond finance, the average annual default rate, the 
risk premium on bonds and the risk premium on loans are set respectively at .61, 7.3, .039, $.027, .022$.

\section{Aggregation}

Define

$$
\begin{gathered}
\psi^{x}\left(q_{t} ; s_{b}, s_{c}, s_{d}\right) \equiv \int_{\frac{s_{b}}{q_{t}}}^{\frac{s_{c}}{q_{t}}} \int_{\frac{s_{d}}{\varepsilon_{1} q_{t}}}(1-\tau) \Phi_{2}\left(d \varepsilon_{2}\right) \Phi_{1}\left(d \varepsilon_{1}\right)+\int_{\frac{s_{c}}{q_{t}}} \Phi_{1}\left(d \varepsilon_{1}\right) \\
\psi^{y}\left(q_{t} ; s_{b}, s_{c}, s_{d}\right) \equiv \int_{\frac{s_{b}}{q_{t}}}^{\frac{s_{c}}{q_{t}}} \int_{\frac{s_{d}}{\varepsilon_{1} q_{t}}}(1-\tau) \varepsilon_{1} \varepsilon_{2} \Phi_{2}\left(d \varepsilon_{2}\right) \Phi_{1}\left(d \varepsilon_{1}\right)+\int_{\frac{s_{c}}{q_{t}}} \varepsilon_{1} \Phi_{1}\left(d \varepsilon_{1}\right) \\
\psi^{a}\left(q_{t} ; s_{b}, s_{c}, s_{d}\right) \equiv \int_{\frac{s_{b}}{q_{t}}}^{\frac{s_{c}}{q_{t}}} \int_{\frac{s_{d}}{\varepsilon_{1} q_{t}}}(1-\tau) \varepsilon_{1} \varepsilon_{2} \Phi_{3}\left(\bar{\omega}^{b}\left(\varepsilon_{1} \varepsilon_{2} q_{t}\right)\right) \Phi_{2}\left(d \varepsilon_{2}\right) \Phi_{1}\left(d \varepsilon_{1}\right)+\int_{\frac{s_{c}}{q_{t}}} \Phi_{2 * 3}\left(\bar{\omega}^{c}\left(\varepsilon_{1} q_{t}\right)\right) \varepsilon_{1} \Phi_{1}\left(d \varepsilon_{1}\right),
\end{gathered}
$$

where $\Phi_{2 * 3}$ is the distribution function for the product $\omega=\varepsilon_{2} \varepsilon_{3}$. Then, total demand for funds, $x_{t}$, total output including agency costs, $y_{t}$, and total output lost to agency costs, $y_{t}^{a}$, are given by equations (28), (29) and (30) in the text.

Now let $\vartheta_{b}\left(\varepsilon_{1}, q_{t} ; s_{d}\right)$ be the average profits per unit of net worth of the bank-financed entrepreneurs, given the shock $\varepsilon_{1}$, aggregate information $q_{t}$, and threshold $s_{d}$ :

$$
\vartheta_{b}\left(\varepsilon_{1}, q_{t} ; s_{d}\right)=(1-\tau)\left[\int_{\frac{s_{d}}{\varepsilon_{1} q_{t}}} \varepsilon_{1} \varepsilon_{2} q_{t} f\left(\bar{\omega}^{b}\left(\varepsilon_{1} \varepsilon_{2} q_{t}\right)\right) \xi \Phi_{2}\left(d \varepsilon_{2}\right)+\Phi_{2}\left(\frac{s_{d}}{\varepsilon_{1} q_{t}}\right)\right] .
$$

Also, let $\vartheta_{c}\left(\varepsilon_{1}, q_{t}\right)$ be the average profits per unit of net worth of the CMF-financed entrepreneurs, given the first idiosyncratic shock $\varepsilon_{1}$, and aggregate information $q_{t}$ :

$$
\vartheta_{c}\left(\varepsilon_{1}, q_{t}\right)=\varepsilon_{1} q_{t} f\left(\bar{\omega}^{c}\left(\varepsilon_{1} q_{t}\right)\right) \xi
$$

Finally, let $\vartheta\left(q_{t} ; s_{b}, s_{c}, s_{d}\right) n_{t}$ be the aggregate profits of the entrepreneurial sector, where

$$
\vartheta\left(q_{t} ; s_{b}, s_{c}, s_{d}\right)=\Phi_{1}\left(\frac{s_{b}}{q_{t}}\right)+\int_{\frac{s_{b}}{q_{t}}}^{\frac{s_{c}}{q_{t}}} \vartheta_{b}\left(\varepsilon_{1}, q_{t} ; s_{d}\right) \Phi_{1}\left(d \varepsilon_{1}\right)+\int_{\frac{s_{c}}{q_{t}}} \vartheta_{c}\left(\varepsilon_{1}, q_{t}\right) \Phi_{1}\left(d \varepsilon_{1}\right) .
$$

The aggregate budget constraint for the entrepreneurs can then be written as equation (31) in the text. 
(a) expected profits

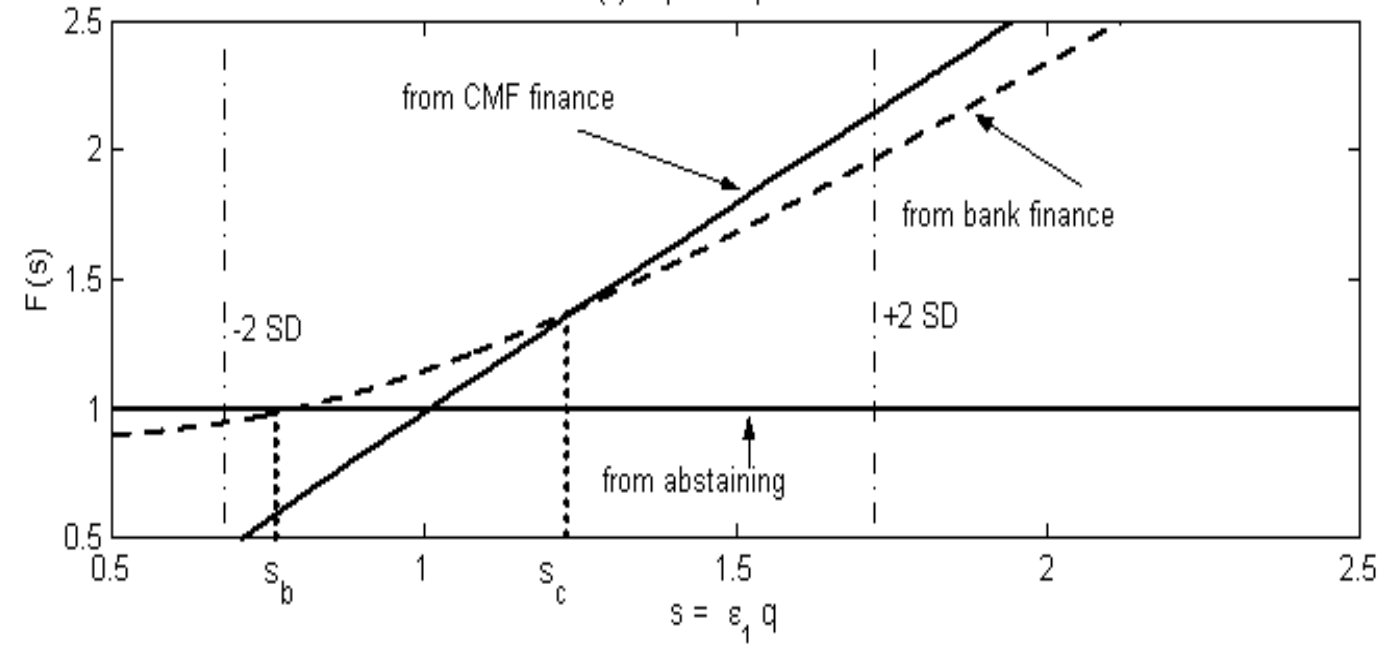

(b) expected profits from bank finance

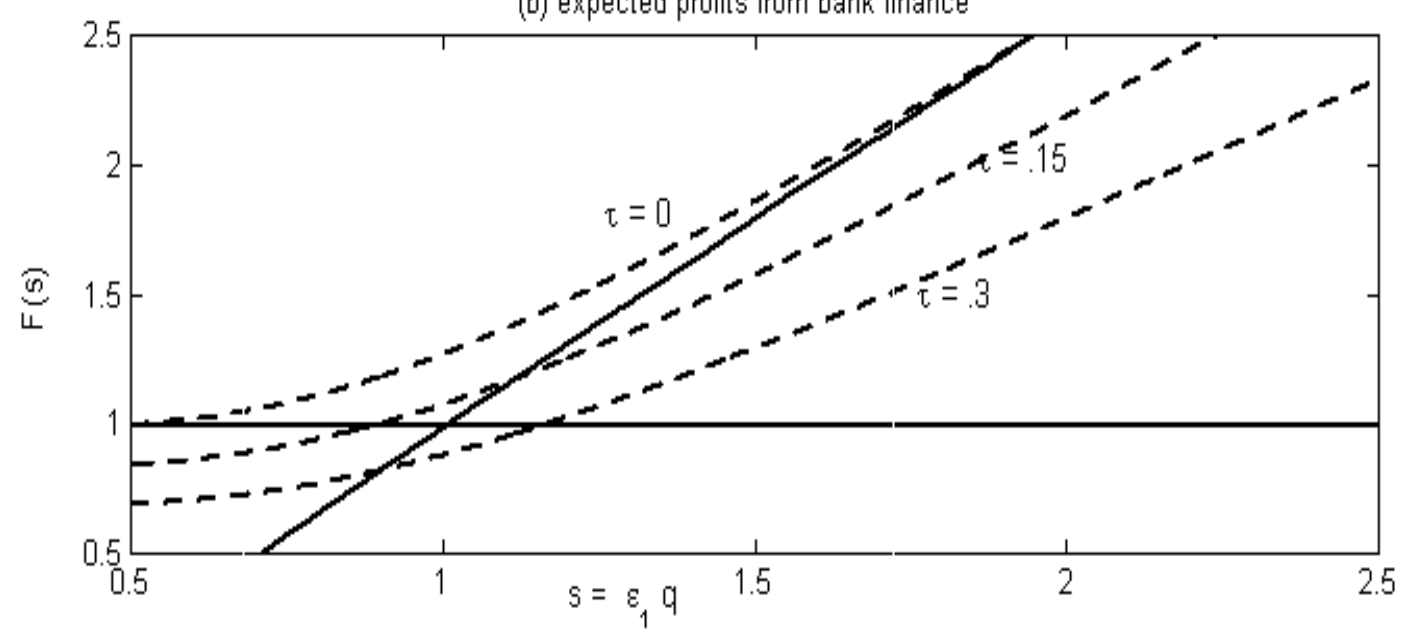

Figure 1: Steady state properties 
(a) distribution of firms

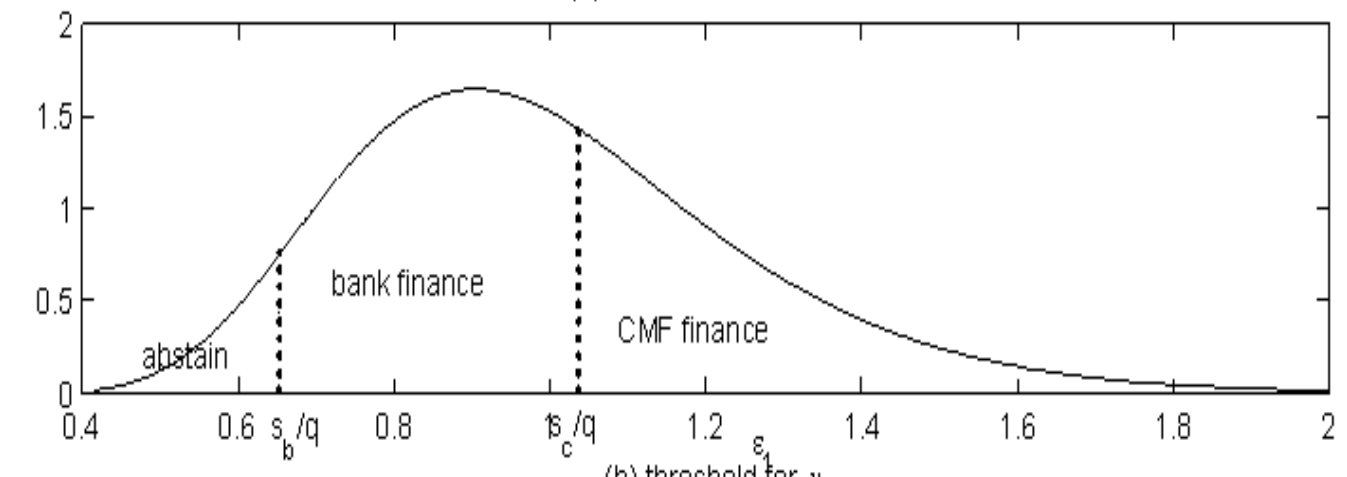

(b) threshold for $v$

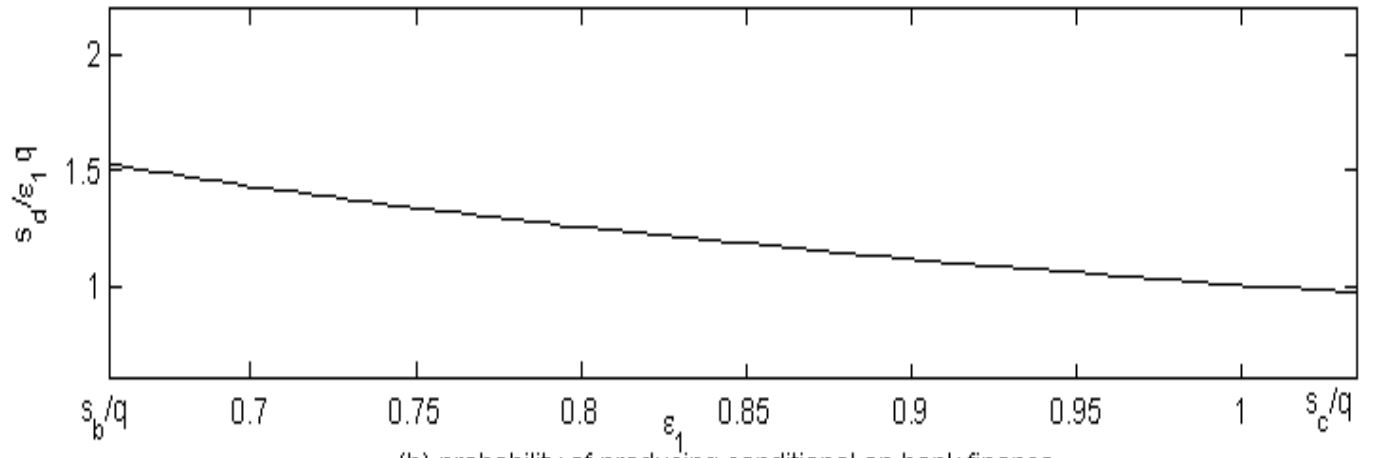

(b) probability of producing conditional on bank finance

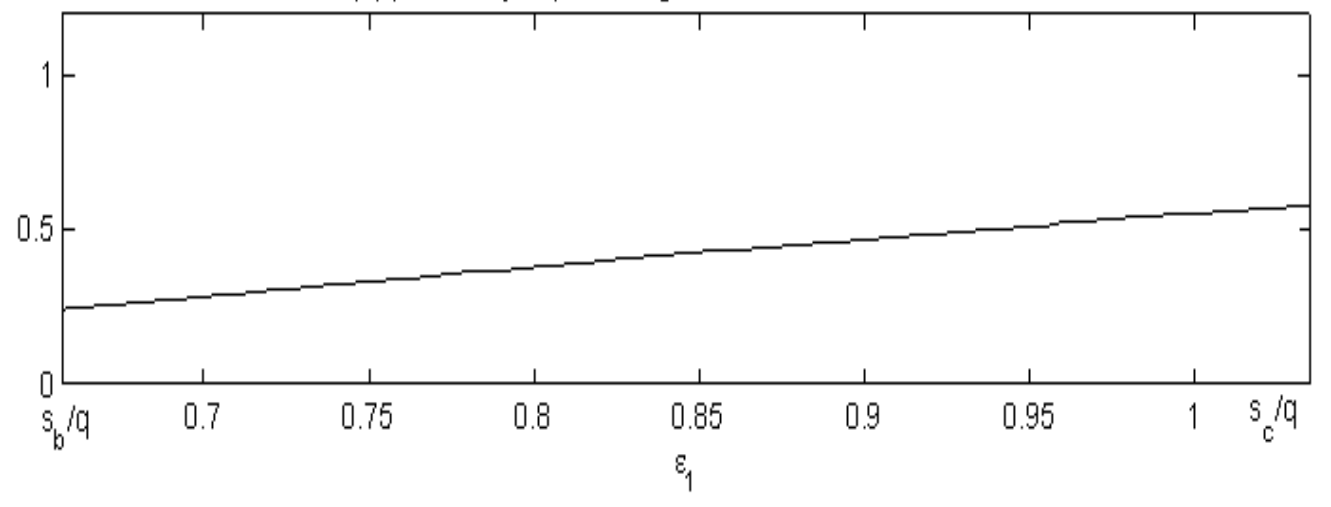

Figure 2: Steady state properties 


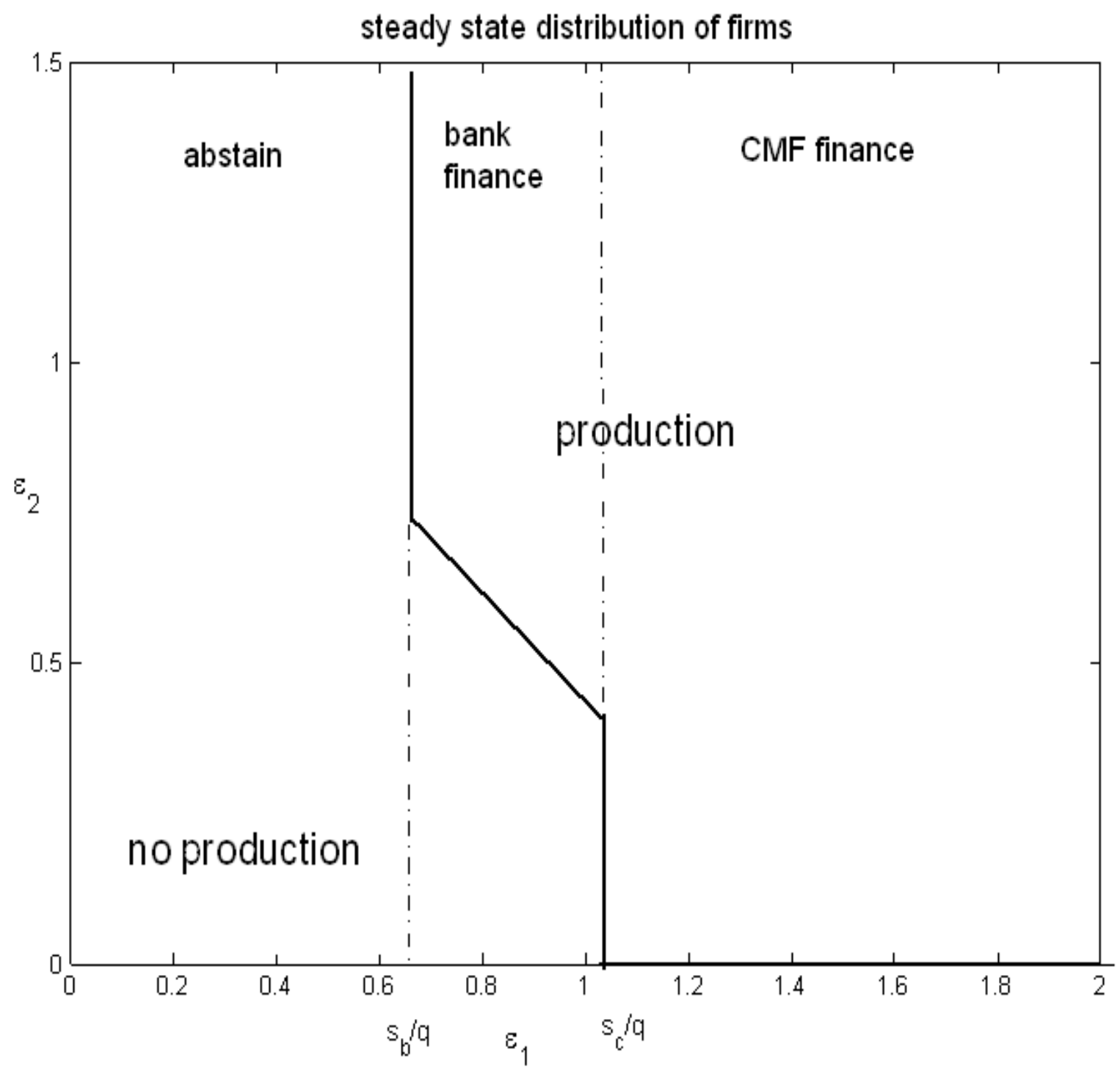

Figure 3: Steady state properties 
Share of firms that:

(a) abstain

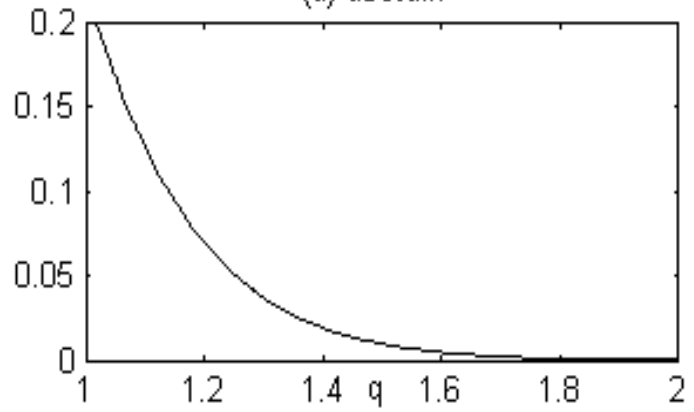

(c) choose CMF finance

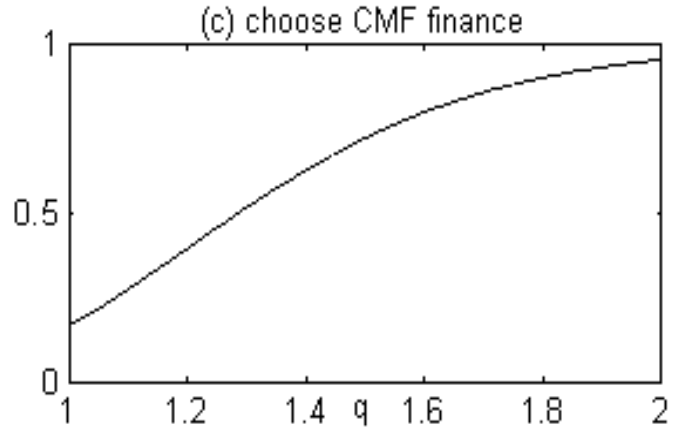

(e) abstain clo banking

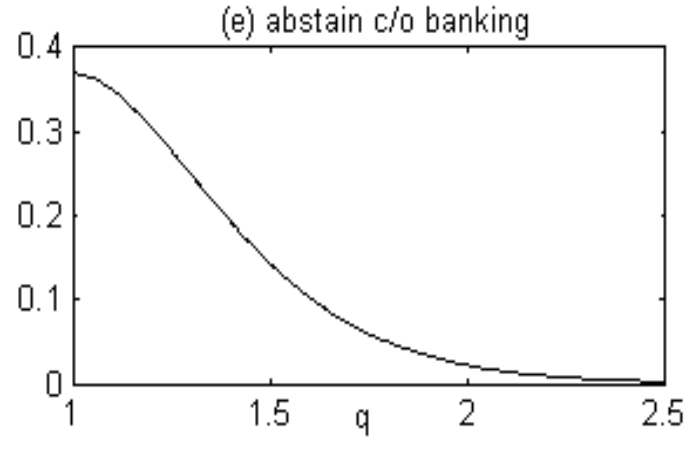

(b) choose bank finance

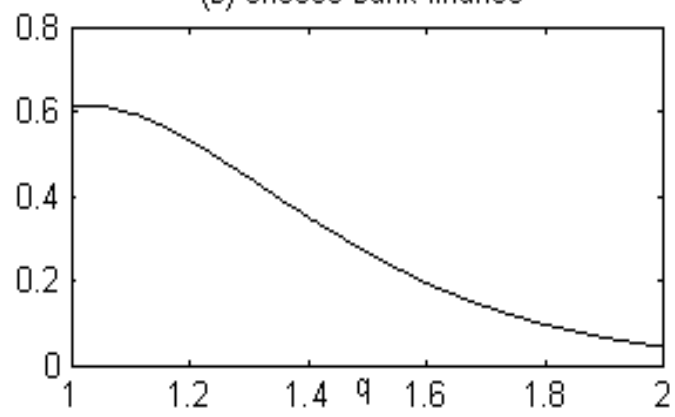

(d) default

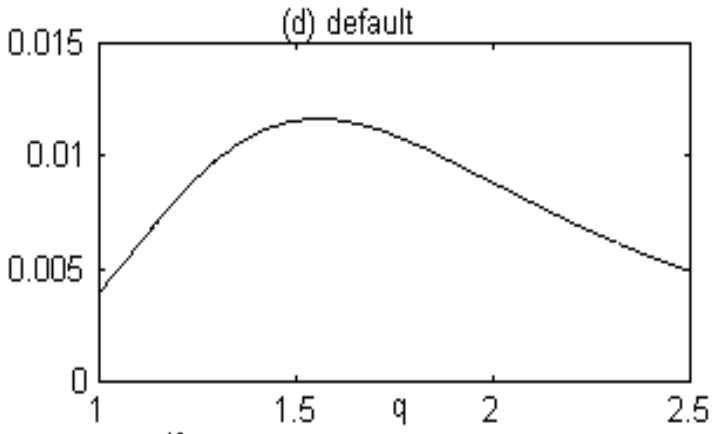

$\times 10^{-16} \quad$ (f) default c/o banking

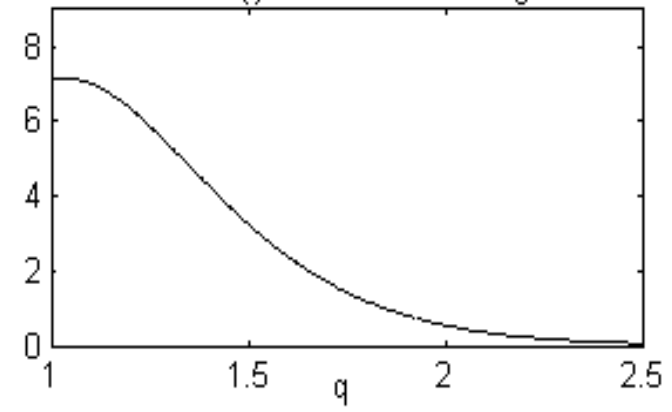

Figure 4: Sensitivity analysis 
(a) changing $\tau$ from 11 to 16
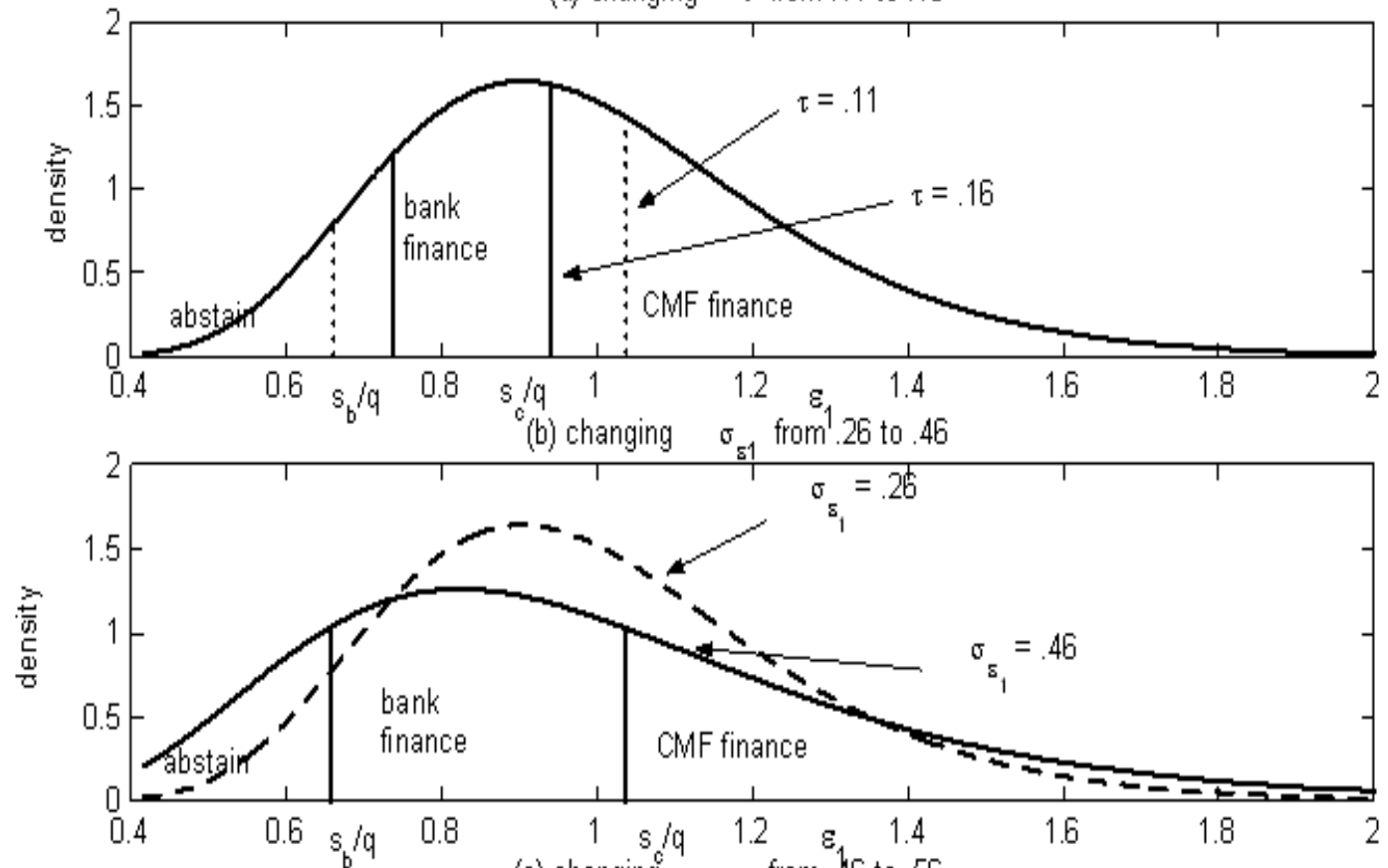

(c) changing $\sigma_{\mathrm{s} 2}$ from .46 to .56

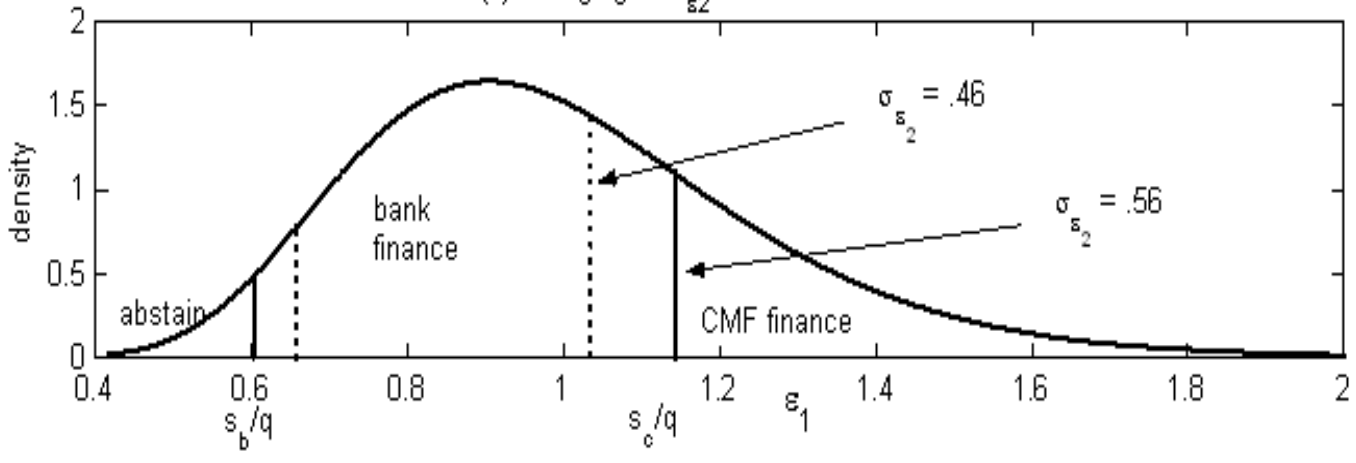

Figure 5: Sensitivity analysis 


\section{References}

[1] Alderson, Michael J. and Betker, Brian L."Liquidation Costs and Capital Structure." Journal of Financial Economics, 1995, 39(1), pp. 45-69.

[2] Altman, Edward I. "A Further Investigation of the Bankruptcy Cost Question." Journal of Finance, 1984, Vol. 39 (4), pp. 1067-89.

[3] Ammer, John and Packer, Frank. "How consistent are credit ratings: a geographic and sectorial analysis of default risk." Board of Governors of the Federal Reserve System, International Finance Discussion Papers, No. 668, June 2000.

[4] Angeloni, Ignazio, Kashyap, Anil and Mojon, Benoit. "The output composition puzzle: a difference in the monetary transmission mechanism in the euro area and the US." NBER Working Paper No. 9985, 2003.

[5] Bernanke, Ben S. and Gertler, Mark. "Agency Costs, Net Worth, and Business Fluctuations." American Economic Review, 1989, LXXIX, pp. 14-31.

[6] Bernanke, Ben S., Gertler, Mark and Gilchrist, Simon. "The Financial Accelerator in a Quantitative Business Cycle Framework." In: Taylor, John B. and Woodford, Michael, eds. Handbook of macroeconomics. Volume 1C. Handbooks in Economics, vol. 15. Amsterdam; New York and Oxford: Elsevier Science, North-Holland, 1999, pp. 1341-93.

[7] Carey, Mark and Nini, Greg. "Is the corporate loan market globally integrated? A pricing puzzle." Mimeo, 2004, Federal Reserve Board, Washington, DC.

[8] Carlstrom, Charles T., and Fuerst, Timothy. "Agency Costs, Net Worth, and Business Cycle Fluctuations: A Computable General Equilibrium Analysis." American Economic Review, 1997, 87(5), pp. 893-910.

[9] Carlstrom, Charles T., and Fuerst, Timothy. "Agency Costs and Business Cycles." Economic Theory, 1998, 12, pp. 583-597.

[10] Carlstrom, Charles T., and Fuerst, Timothy. "Monetary Shocks, Agency Costs and Business Cycles." Carnegie Rochester Conference Series on Public Policy, 2001, 54(0),pp. 1-27.

[11] Cecchetti, Stephen G.: "Legal structure, financial structure and the monetary policy transmission mechanism." NBER Working Paper, No. 7151, June 1999. 
[12] Chemmanur, Thomas J. and Fulghieri, Paolo. "Reputation, Renegotiation, and the Choice between Bank Loans and Publicly Traded Debt." Review of Financial Studies, 1994, 7(3), pp. $475-506$.

[13] Christiano, Lawrence, Motto, Roberto and Rostagno, Massimo. "The Great Depression and the Friedman and Schwartz Hypothesis." ECB Working Paper Series, 2004, n. 326.

[14] Cooley, Thomas F. and Quadrini, Vincenzo." Monetary Policy and the Financial Decisions of Firms." Mimeo, 1999.

[15] Ehrmann, Michael, Giambacorta, Leonardo, Martinez-Pages, Jorge and Andreas Worms.” Financial systems and the role of banks in monetary policy transmission in the euro area." In: Angeloni, Ignazio, Kashyap, Anil and Mojon, Benoit, eds. Monetary Policy Transmission in the Euro Area, 2003, Cambridge University Press.

[16] English, William and William Nelson. "Bank Risk Rating of Business Loans." Mimeo, Federal Reserve Board, Washington, US, 1998.

[17] Faia, Ester. "Monetary Policy in a World with Different Financial Systems." ECB Working Paper 183, 2002.

[18] Gale, Dale and Hellwig, Martin. "Incentive-Compatible Debt Contracts: The One-Period Problem." The Review of conomic Studies, 1985, 52(4), pp. 647-663.

[19] Helwege, Jean and Kleiman, Paul. "Understanding Aggregate Deafault Rates of High Yield Bonds." Current Issues in Economics and Finance, 2(6), May 1996. Federal Reserve Bank of New York.

[20] Holstrom, Bengt and Tirole, Jean. "Financial Intermediation, Loanable Funds, and the Real sector." The Quarterly Journal of Economics, 1997, CXII(3), pp. 663-691.

[21] Kiyotaki, Nobuhiro and Moore, John. "Credit cycles." Journal of Political Economy, 1997, 105(2), pp. 211-48.

[22] Mahajan, Arvind, and Fraser, Donald. "Dollar Eurobond pricing and US bond pricing." Journal of International Business Studies, 1986, 17, pp. 21-37.

[23] Masulis, Ronald. W. "The impact of Capital Structure Change on Firm Value: Some Estimates." Journal of Finance, 1983, 38, pp. 107-26. 
[24] Moody's Investors Service. "Relative Default Rates on Corporate Loans and Bonds." Special Comment, September 2003.

[25] Santos, Joāo, A.C. and Tsatsaronis, Kostas. "The cost of barriers to entry: evidence from the market for corporate euro bond underwriting." BIS Working Papers, No. 134, September 2003.

[26] Townsend, Robert M. "Optimal Contracts and Competitive Markets with Costly State Verification." Journal of Economic Theory, 1979, 21(2), pp. 265-93.

[27] Warner, Jerald. "Bankruptcy Costs: Some Evidence." Journal of Finance, 1977, 32(2), pp. 337-48. 


\section{SFB 649 Discussion Paper Series}

For a complete list of Discussion Papers published by the SFB 649, please visit http://sfb649.wiwi.hu-berlin.de.

001 "Nonparametric Risk Management with Generalized Hyperbolic Distributions" by Ying Chen, Wolfgang Härdle and Seok-Oh Jeong, January 2005.

002 "Selecting Comparables for the Valuation of the European Firms" by Ingolf Dittmann and Christian Weiner, February 2005.

003 "Competitive Risk Sharing Contracts with One-sided Commitment" by Dirk Krueger and Harald Uhlig, February 2005.

004 "Value-at-Risk Calculations with Time Varying Copulae" by Enzo Giacomini and Wolfgang Härdle, February 2005.

005 "An Optimal Stopping Problem in a Diffusion-type Model with Delay" by Pavel V. Gapeev and Markus Reiß, February 2005.

006 "Conditional and Dynamic Convex Risk Measures" by Kai Detlefsen and Giacomo Scandolo, February 2005.

007 "Implied Trinomial Trees" by Pavel Čížek and Karel Komorád, February 2005.

008 "Stable Distributions" by Szymon Borak, Wolfgang Härdle and Rafal Weron, February 2005.

009 "Predicting Bankruptcy with Support Vector Machines" by Wolfgang Härdle, Rouslan A. Moro and Dorothea Schäfer, February 2005.

010 "Working with the XQC" by Wolfgang Härdle and Heiko Lehmann, February 2005.

011 "FFT Based Option Pricing" by Szymon Borak, Kai Detlefsen and Wolfgang Härdle, February 2005.

012 "Common Functional Implied Volatility Analysis" by Michal Benko and Wolfgang Härdle, February 2005.

013 "Nonparametric Productivity Analysis" by Wolfgang Härdle and Seok-Oh Jeong, March 2005.

014 "Are Eastern European Countries Catching Up? Time Series Evidence for Czech Republic, Hungary, and Poland" by Ralf Brüggemann and Carsten Trenkler, March 2005.

015 "Robust Estimation of Dimension Reduction Space" by Pavel Čížek and Wolfgang Härdle, March 2005.

016 "Common Functional Component Modelling" by Alois Kneip and Michal Benko, March 2005.

017 "A Two State Model for Noise-induced Resonance in Bistable Systems with Delay" by Markus Fischer and Peter Imkeller, March 2005.

SFB 649, Spandauer Straße 1, D-10178 Berlin http:/ / sfb649.wiwi.hu-berlin.de

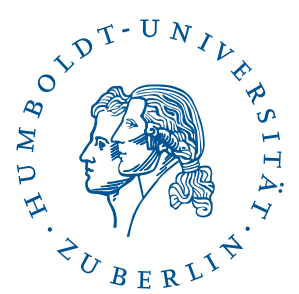


018 "Yxilon - a Modular Open-source Statistical Programming Language" by Sigbert Klinke, Uwe Ziegenhagen and Yuval Guri, March 2005.

019 "Arbitrage-free Smoothing of the Implied Volatility Surface" by Matthias R. Fengler, March 2005.

020 "A Dynamic Semiparametric Factor Model for Implied Volatility String Dynamics" by Matthias R. Fengler, Wolfgang Härdle and Enno Mammen, March 2005.

021 "Dynamics of State Price Densities" by Wolfgang Härdle and Zdeněk Hlávka, March 2005.

022 "DSFM fitting of Implied Volatility Surfaces" by Szymon Borak, Matthias R. Fengler and Wolfgang Härdle, March 2005.

023 "Towards a Monthly Business Cycle Chronology for the Euro Area" by Emanuel Mönch and Harald Uhlig, April 2005.

024 "Modeling the FIBOR/EURIBOR Swap Term Structure: An Empirical Approach" by Oliver Blaskowitz, Helmut Herwartz and Gonzalo de Cadenas Santiago, April 2005.

025 "Duality Theory for Optimal Investments under Model Uncertainty" by Alexander Schied and Ching-Tang Wu, April 2005.

026 "Projection Pursuit For Exploratory Supervised Classification" by Eun-Kyung Lee, Dianne Cook, Sigbert Klinke and Thomas Lumley, May 2005.

027 "Money Demand and Macroeconomic Stability Revisited" by Andreas Schabert and Christian Stoltenberg, May 2005.

028 "A Market Basket Analysis Conducted with a Multivariate Logit Model" by Yasemin Boztuğ and Lutz Hildebrandt, May 2005.

029 "Utility Duality under Additional Information: Conditional Measures versus Filtration Enlargements" by Stefan Ankirchner, May 2005.

030 "The Shannon Information of Filtrations and the Additional Logarithmic Utility of Insiders" by Stefan Ankirchner, Steffen Dereich and Peter Imkeller, May 2005.

031 "Does Temporary Agency Work Provide a Stepping Stone to Regular Employment?" by Michael Kvasnicka, May 2005.

032 "Working Time as an Investment? - The Effects of Unpaid Overtime on Wages, Promotions and Layoffs" by Silke Anger, June 2005.

033 "Notes on an Endogenous Growth Model with two Capital Stocks II: The Stochastic Case" by Dirk Bethmann, June 2005.

034 "Skill Mismatch in Equilibrium Unemployment" by Ronald Bachmann, June 2005.

\section{SFB 649, Spandauer Straße 1, D-10178 Berlin} http:/ / sfb649.wiwi.hu-berlin.de

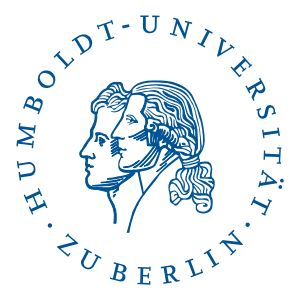


035 "Uncovered Interest Rate Parity and the Expectations Hypothesis of the Term Structure: Empirical Results for the U.S. and Europe" by Ralf Brüggemann and Helmut Lütkepohl, April 2005.

036 "Getting Used to Risks: Reference Dependence and Risk Inclusion" by Astrid Matthey, May 2005.

037 "New Evidence on the Puzzles. Results from Agnostic Identification on Monetary Policy and Exchange Rates." by Almuth Scholl and Harald Uhlig, July 2005.

038 "Discretisation of Stochastic Control Problems for Continuous Time Dynamics with Delay" by Markus Fischer and Markus Reiss, August 2005.

039 "What are the Effects of Fiscal Policy Shocks?" by Andrew Mountford and Harald Uhlig, July 2005.

040 "Optimal Sticky Prices under Rational Inattention" by Bartosz Maćkowiak and Mirko Wiederholt, July 2005.

041 "Fixed-Prize Tournaments versus First-Price Auctions in Innovation Contests" by Anja Schöttner, August 2005.

042 "Bank finance versus bond finance: what explains the differences between US and Europe?" by Fiorella De Fiore and Harald Uhlig, August 2005.

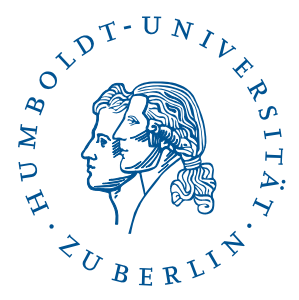

